\title{
Metallomics
}

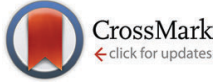

Cite this: Metallomics, 2016, 8,313 Accepted 25th January 2016

DOI: $10.1039 / \mathrm{c} 5 \mathrm{mt} 00295 \mathrm{~h}$

www.rsc.org/metallomics
Received 17th November 2015,

\section{Interplay between seven secondary metal uptake systems is required for full metal resistance of Cupriavidus metallidurans $\dagger$}

\author{
M. Herzberg, L. Bauer, A. Kirsten and D. H. Nies*
}

\begin{abstract}
The beta-proteobacterium Cupriavidus metallidurans is able to grow in metal-contaminated environments due to having sophisticated metal efflux systems. Here, the contribution of all seven known secondary metal uptake systems (ZupT, PitA, CorA $1, \operatorname{CorA}_{2}, \operatorname{CorA}_{3}, \mathrm{ZntB}, \mathrm{HoxN}$ ) to metal resistance is characterized. In a strategic deletion approach, all ten double deletion mutants, a variety of triple and quadruple mutants,

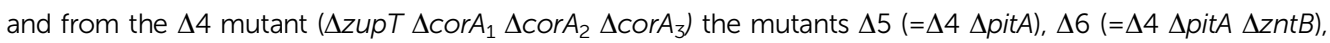
and finally $\Delta 7$ ( $\Delta$ zupT $\Delta \operatorname{cor}_{1} \Delta \operatorname{cor}_{2} \Delta \operatorname{cor}_{3} \Delta$ pitA $\left.\Delta z n t B \Delta h o x N\right)$ were constructed. Metal resistance, metal content, and regulation of expression of these genes were characterized in these mutants. The $\Delta z u p T$ single deletion strain exhibited an extended lag phase in Tris-buffered liquid mineral salts medium (TMM) compared to its parent strain AE104, indicating a decreased fitness level. Further deletions up to $\Delta 6$ did not influence growth in TMM without added metals but fitness of the $\Delta 7$ strain dropped to a lower level compared to $\Delta 6, \Delta 5$ and $\Delta z u p T$. The cells of the $\Delta 7$ multiple deletion strain still contained all essential metals, demonstrating that additional metal import systems must exist in C. metallidurans. PitA was an important contributor of metal:phosphate complexes to C. metallidurans. Up to $\Delta 5$ no evidence was found for increased expression of the transporter genes to recruit substitutes for the deleted importers. Only the hox $N$-lacZ reporter gene fusion displayed a changed expression pattern in the $\Delta 6$ strain, indicating recruitment of HoxN. Metal resistance of the deletion strains decreased along the deletion series although all strains still contained metal efflux systems: up to the $\Delta 6$ mutant the overall fitness was kept at the $\Delta$ zupT mutant strain level at the cost of a diminished competence to handle $\mu \mathrm{M}$ concentrations of transition metals. Together, these data demonstrated an important contribution of the seven secondary metal import systems to metal homeostasis in this bacterium.
\end{abstract}

\section{Introduction}

The beta-proteobacterium Cupriavidus metallidurans owes its outstanding ability to survive in environments with high concentrations of transition metals to the possession of a variety of sophisticated heavy metal-resistance determinants. ${ }^{1-4}$ Central to these are metal efflux systems that have been characterized in detail in the last decades. ${ }^{5-7}$ Members of the $\mathrm{P}_{\mathrm{IB}}$-type ATPase (TC\#3.A.3), CDF (TC\#2.A.4) or other transporter families $\{$ TC, transporter classification $\left.{ }^{8-10}\right\}$ remove surplus transition metal cations from the cytoplasm to the periplasm. Transenvelope protein complexes containing RND proteins (TC\#2.A.6), such as CzcCBA or CnrCBA as major component, are responsible in vivo for further export from the periplasm to the external medium. ${ }^{1,5,7,11}$ Substrates of these efflux systems are metal cations that have been

Molecular Microbiology, Institute for Biology/Microbiology, Martin-Luther-University, Halle-Wittenberg, Germany. E-mail: d.nies@mikrobiologie.uni-halle.de

$\dagger$ Electronic supplementary information (ESI) available. See DOI: 10.1039/c5mt00295h imported by metal uptake systems, which are thus interaction partners of the exporters. uptake systems to metal resistance in C. metallidurans has not been characterized in detail. The genome of $C$. metallidurans predicts at least seven secondary uptake systems for transition metals: (i) the ZIP protein ZupT (TC\#2.A.5); (ii) the metal: phosphate importer PitA (TC\#2.A.20); (iii) three members of the MIT family CorA $\mathrm{A}_{1}$ through $\mathrm{CorA}_{3}$ (TC\#1.A.35); (iv) the additional MIT protein ZntB that might be an uptake or efflux system; (v) and the NiCoT protein HoxN (TC\#2.A.52) that might import additional $\mathrm{Ni}^{2+}$ cations into the cell for hydrogenase synthesis. ${ }^{1,11,12}$ C. metallidurans ${ }^{13}$ does not possess orthologs of the ABC-type (TC\#3.A.1) import systems ZnuABC and NikABC from $E$. coli for zinc or nickel import, respectively, ${ }^{14-16}$ so that the secondary transport systems should theoretically have an important role in the uptake of transition metal cations.

Using single gene deletion mutants and a $\Delta z u p T \Delta$ pitA double mutant, it could be demonstrated that neither of the
In contrast to the efflux systems, contribution of the metal 
five systems ZupT, PitA, $\operatorname{CorA}_{1}$, CorA 2 or $\operatorname{CorA}_{3}$ alone was essential for the import of zinc or other transition metal ions. ${ }^{13}$ Moreover, none of these systems pairs up with an efflux system to form a regulated "shunt" of a metal through the cell. Such a shunt might considerably have maintained the cytoplasmic concentration of a metal in homeostasis, by either increased export or increased import of the metal if its concentration would be too high or too low, respectively. Instead, these five import systems possibly form a battery of redundant uptake systems with low and overlapping substrate specificities, which supplies metals to the cell as they become available, relying on the subsequent efflux system to cope with any surplus. In this way, the exact composition of the cytoplasmic metal content and mélange composition is maintained in a way that minimizes negative interference between the individual metals. ${ }^{13}$

Expression of $z u p T, \operatorname{cor} A_{1}-\operatorname{cor} A_{3}$ and pitA is down-regulated by zinc excess. Only expression of zupT is up-regulated by zinc starvation via the Fur-type zinc uptake regulator Zur (previously FurC). ${ }^{17}$ Expression of $\operatorname{cor}_{1}$ is influenced by magnesium starvation. ${ }^{13}$ The pitA gene is up-regulated with increasing phosphate concentrations up to $5 \mathrm{mM}$ phosphate, which complexes zinc ions and lowers its availability. At higher phosphate concentrations, pitA is downregulated again but remains on a high expression level in a $\Delta z u p T$ mutant, ${ }^{13}$ indicating a central function of zinc in control of expression of pitA; Zur is not involved in this process. ${ }^{17}$

The ZupT importer of Escherichia coli has a broad substrate specificity. ${ }^{18-20}$ Deletion of its ortholog in C. metallidurans does not impair net import of $\mathrm{Zn}$ (II) or any other metal ${ }^{13}$ at least not at the first glance. A more detailed analysis, however, reveals a pleiotropic effect of the $\Delta z u p T$ deletion: (i) the mutant cell is no longer able to import Zn(II) at low zinc concentrations, ${ }^{13}$ e.g. in the presence of the metal chelator ethylene-diamine-tetra-acetic acid (EDTA); (ii) the overall zinc content of the mutant cell cultivated in minerals salts medium amounts to about 20000 zinc per cell while the parent contains 70000 zinc per cell; ${ }^{21}$ (iii) zinc cannot be efficiently allocated to the zinc-dependent beta-prime subunit RpoC of the RNA polymerase, leading to aggregation of RpoC into inclusion bodies; ${ }^{21}$ (iv) the central CzcA subunit of the RND-driven transenvelope complex CzcCBA is either not translated or is rapidly degraded; ${ }^{21}$ (v) surprisingly zinc is not efficiently allocated to the periplasmic $\mathrm{Cu}-\mathrm{Zn}$ superoxide dismutase SodC; $;^{21,22}$ and (vi) a part of a genomic island that is silenced as a response to metal stress in the parent strain AE104 is un-silenced again in the $\Delta z u p T$ mutant. ${ }^{23}$ So, the effect of the single $\Delta z u p T$ gene deletion revealed interesting phenomena upon close inspection. We ask here what more can be learned if all seven currently known secondary metal uptake systems are removed from the $C$. metallidurans cell.

\section{Results}

Deletion of seven genes for metal uptake systems decreases fitness of the resulting $\Delta 7$ mutant strain

All seven recognizable genes for secondary metal uptake systems (zupT, pitA, $\operatorname{cor}_{1}, \operatorname{cor}_{2}, \operatorname{cor}_{3}, z n t B$, hoxN) were deleted from the chromosome of the plasmid-free C. metallidurans strain AE104. This plasmid-free derivative was used as parent instead of C. metallidurans $\mathrm{CH} 34$ wild type to avoid interference through the plasmid-encoded metal efflux systems, and because the $c z c$ containing plasmid pMOL30 was unstable in a $\triangle z u p T$ mutant. $^{21}$ Starting with the five genes zupT, pitA, $\operatorname{cor}_{1}, \operatorname{corA}_{2}$ and $\operatorname{cor}_{3}$, all ten combinations of double mutants and four of the five possible quadruple mutants but only two triple mutants were constructed. During construction of the mutants, it was only once possible to obtain a "clean" (antibiotic marker-free deletion) $\Delta c o r A_{1}$ deletion, in this case from the $\Delta z u p T \Delta \operatorname{corA}_{2} \Delta \operatorname{corA}_{3}$ triple deletion strain leading to the $\Delta z u p T \Delta \operatorname{cor}_{1} \Delta \operatorname{corA}_{2} \Delta \operatorname{cor}_{3}$ quadruple mutant, designated $\Delta 4$. In all other cases, the $\operatorname{cor} A_{1}$ gene had to be interrupted by insertion of a kanamycin resistance cassette. The "clean" quadruple deletion strain $\Delta 4$ was the parent of $\Delta 5(=\Delta 4$ $\Delta$ pitA), $\Delta 6$ (= $=\Delta 4$ pitA $\Delta z n t B)$ and finally $\Delta 7(=\Delta 4 \Delta$ pitA $\Delta z n t B$ $\Delta$ hoxN $=\Delta$ zupT $\Delta$ pitA $\left.\Delta \operatorname{corA}_{1} \Delta \operatorname{corA}_{2} \Delta \operatorname{corA}_{3} \Delta z h t B \Delta h o x N\right)$.

The fitness of the mutant strains $\Delta z u p T, \Delta 5, \Delta 6$ and $\Delta 7$ was compared to that of the parent strain AE104 in Tris-buffered mineral salts medium (TMM) without added metals. As already reported, ${ }^{22}$ the $\Delta z$ upT strain showed an extended lag phase compared to strain AE104 (Fig. 1A and Fig. S1A, ESI $\dagger$ ). The lag phase of the $\Delta 7\left(\Delta z u p T \Delta\right.$ pitA $\Delta \operatorname{cor}_{1} \Delta \operatorname{corA}_{2} \Delta \operatorname{corA}_{3} \Delta z n t B$ $\Delta$ hoxN) mutant strain was even more extended, while growth curves of the $\Delta 5\left(\Delta z u p T \Delta\right.$ pitA $\left.\Delta \operatorname{corA}_{1} \Delta \operatorname{corA}_{2} \Delta \operatorname{corA}_{3}\right)$ and $\Delta 6$ $\left(\Delta z\right.$ upT $\Delta$ pitA $\left.\Delta \operatorname{corA}_{1} \Delta \operatorname{corA}_{2} \Delta \operatorname{corA}_{3} \Delta z n t B\right)$ mutants were not different from that of the $\Delta z u p T$ strain. While removal of the

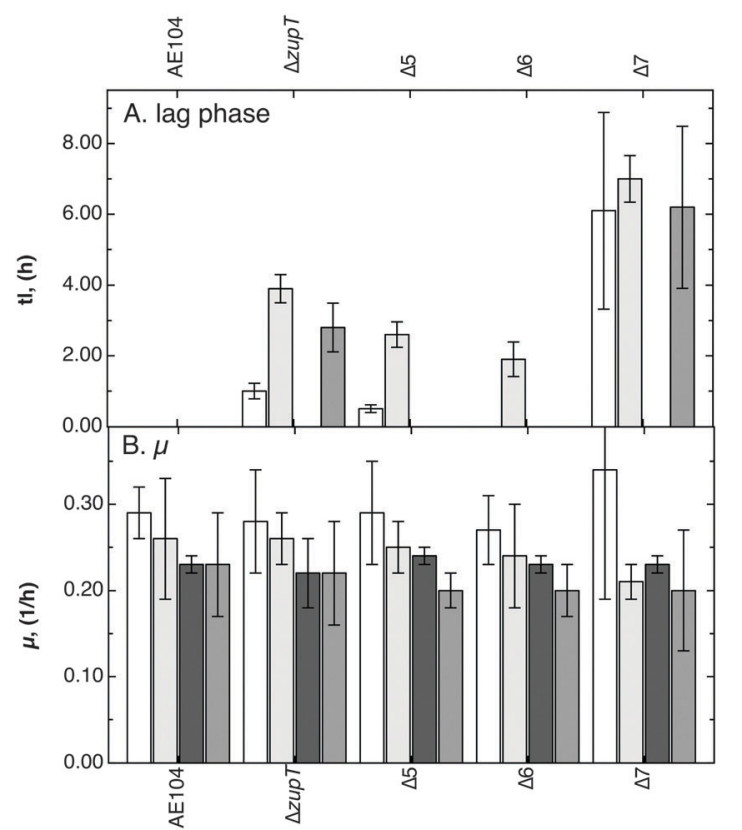

Fig. 1 Growth impairment of the mutant strains. The strains AE104, $\Delta$ zupT, $\Delta 5, \Delta 6$ or $\Delta 7$ were cultivated in TMM at $30{ }^{\circ} \mathrm{C}$ without further additions (white bars) or in the presence of $10 \mu \mathrm{M}$ Co(II) (light grey bars),

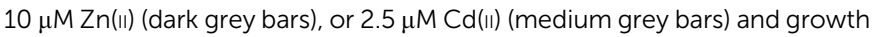
was measured as turbidity at $600 \mathrm{~nm}$. The duration of the lag phase (panel A) and the growth rates (panel B) were calculated. Growth curves in Fig. S1 $(E S I \dagger)$, data for the lag phase and growth rate in a table below Fig. S1 (ESI $)$. $n \geq 3$, deviation bars indicated. 
important zinc importer ZupT decreased fitness of $C$. metallidurans to a first level, the cells were able to compensate for deletion of an additional 5 genes leading to the $\Delta 6$ strain but not that of the 6th gene leading to the $\Delta 7$ strain. This decreased fitness to a second level, highlights the importance of the battery of seven metal importers for metal homeostasis of C. metallidurans.

\section{Metal content of the deletion strains}

The cells of the $\Delta 7$ multiple deletion strain still contained all essential metals, clearly indicating that additional metal import systems must exist in C. metallidurans (Fig. 2 and Table S1, ESI $\dagger$ ). These are likely to be primary importers or members of currently unknown uptake systems.

As published,$^{21}$ deletion of zupT resulted in a decreased zinc content visible in all $\Delta z u p T$-containing multiple deletion strains up to $\Delta 7$ (Fig. 2). Except in these $\Delta z u p T$ mutants, C. metallidurans cells were always able to compensate for the loss of a metal uptake system by adopting other systems, which altered the cellular metal content to some degree. First, also as published, ${ }^{13}$ deletion of pitA led to a 3 -fold increase in magnesium (and phosphorus) content in the $\Delta z u p T \Delta p i t A$ double deletion strain of AE104. An increased magnesium content was also a feature of all investigated $\Delta$ pitA-containing multiple deletion strains up to $\Delta 7$ (Fig. 2). Second, deletion of pitA in $\Delta 4$ leading to $\Delta 5$ additionally increased the zinc, but decreased the iron, copper and nickel content. This indicated some re-arrangement of metal import of $\Delta 5$ compared to $\Delta 4$ as a result of the pitA deletion. Importers of magnesium and zinc were increasingly used in the $\Delta 5$ strain while the decreased iron, copper and nickel content did not stimulate additional import of these metals, e.g. by up-regulation of iron import pathways via FurA or FurB. ${ }^{17}$ Third, while deletion of zntB from $\Delta 5$ (leading to $\Delta 6$ ) had no significant effect on the metal content (Fig. 2), deletion of hox $N$ in $\Delta 6$ (leading to $\Delta 7$ ) increased the magnesium content, restored the iron and copper content to the higher and the zinc content to the lower level of the $\Delta 4$ strain.

The cellular cobalt content decreased when pitA was deleted from the parent strain AE104. Together with the lowered iron, copper and nickel content of the $\Delta 5$ strain $(=\Delta 4 \Delta p i t A)$ compared to $\Delta 4$, this indicated that PitA may be an important contributor of iron, copper, nickel and cobalt in the form of the metal:phosphate complexes to C. metallidurans.

\section{Metal resistance of the deletion strains}

The deletion strains up to $\Delta 7$ were still able to import all essential transition metals, probably due to use of other uptake pathways (Fig. 2 and Table S1, ESI $\dagger$ ). All deletion mutants of the parent strain AE104 still contained the genes for the metalexporting $\mathrm{P}_{\mathrm{IB} 2}$-type ATPases ZntA and CadA, for three copperexporting $\mathrm{P}_{\mathrm{IB} 1}$-type ATPases such as CupA, and the two CDF proteins DmeF and FieF, which together should maintain a minimum zinc, cadmium, copper, cobalt and nickel resistance. ${ }^{7}$ If efficient physiological function of these efflux systems requires a balanced import of metals by the seven secondary importers, successive removal of importers should lead to increased imbalance in the import of transition metals, eventually to incompetence of the efflux systems, and ultimatively to loss of metal resistance. To test this hypothesis, metal resistance of the deletion strains was analyzed in growth curves, liquid culture and on solid agar medium.

On solid TMM there was no significant effect in any of the studied multiple deletion strains on zinc, cadmium or copper resistance (Table S2, ESI $\dagger$ ). Nickel resistance of all $\Delta \operatorname{cor}_{1}$ containing multiple mutant strains was enhanced. In addition, the $\Delta z u p T \Delta$ pitA $\Delta \operatorname{corA}_{2} \Delta \operatorname{cor}_{3}$ mutant, which still possessed a functional $\operatorname{cor}_{1}$ gene, was also more resistant to nickel than the parent strain AE104, while its direct parent, the triple mutant $\Delta z$ zup $\Delta$ pitA $\Delta \operatorname{corA}_{3}$, was not (Table S2, ESI $\dagger$ ). Together with the low nickel content of the $\Delta 4$ and $\Delta 5$ mutant strains cultivated in non-amended TMM (Fig. 2), this indicated that CorA $_{1}$ was involved in nickel uptake but needed the $\operatorname{CorA}_{2}$ protein for full function. Due to the fact that CorA-like proteins are pentamers ${ }^{24}$ and TMM-grown C. metallidurans cells contain

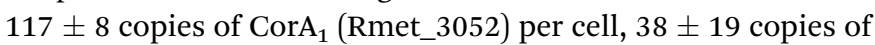
CorA $_{2}$ (Rmet_0036) and $37 \pm 5$ copies of CorA 3 (Rmet_3287), yielding a $3.2 \pm 0.2: 1.0 \pm 0.5: 1 \pm 0.1$ ratio of $\operatorname{CorA}_{1}: \operatorname{CorA}_{2}$ : $\mathrm{CorA}_{3},{ }^{22}$ this could mean that the CorAs of $C$. metallidurans form heteromultimers, as has been described for other metal transporters. $^{25}$

The determination of the MIC values to cobalt in all $\Delta z u p T$ $\triangle$ corA and $\Delta$ pitA $\Delta$ corA-containing double mutants were hampered by high deviations of the individual measurements. Cobalt resistance of two double mutants, $\Delta \operatorname{cor}_{1} \Delta \operatorname{cor}_{2}$ and $\Delta \operatorname{cor}_{2}$ $\Delta c o r A_{3}$ was very low, while that of the $\operatorname{cor}_{123}$ triple mutant was higher than that of the parent strain AE104. Resistance of the three single $\Delta$ corA deletion strains was similar to the AE104 level (Table S2, ESI $\dagger$ ). This could mean that a putative heteropentameric complex composed of two CorA species is able to function if PitA and ZupT are additionally present, whereas the presence of $\mathrm{CorA}_{3}$ or CorA $\mathrm{A}_{1}$ alone results in a strongly decreased cobalt resistance. The three CorAs of $C$. metallidurans could be assigned to the import of nickel and cobalt, maybe in the form of a heteromultimeric complex CorA $_{123}$, which interacts with ZupT and PitA as main metal supply routes in C. metallidurans.

Analysis of metal resistance of the mutants up to $\Delta 5$ on solid growth medium did not yield further insights and the study was continued using liquid TMM together with low concentrations of $\mathrm{Zn}$ (II), Co(II) or Cd(II) (Fig. 1 and Fig. S1, ESI $\dagger$ ). The extended lag phase of the $\Delta z u p T$ mutant compared to the parent AE104 increased when $10 \mu \mathrm{M} \operatorname{Co}(\mathrm{II})$ or $2.5 \mu \mathrm{M} \mathrm{Cd}(\mathrm{II})$ was added while addition of $10 \mu \mathrm{M} \mathrm{Zn}$ (II) ameliorated the effect of the $\Delta z u p T$ deletion. Growth of the $\Delta 5$ and the $\Delta 6$ mutant strains was similar to that of the $\Delta z u p T$ strain or was even better in the case of added cadmium. As in the case of non-amended medium (Fig. 1), deletion of pitA, $\operatorname{cor}_{123}$ and $z n t B$ in addition to $\Delta z u p T$ did not impair fitness of the $C$. metallidurans strains further because the cells were able to compensate for the loss of these importers. However, in $\Delta 7$ resistance to cobalt and cadmium was significantly decreased (Fig. 1 and Fig. S1, ESI $\dagger$ ), while zinc resistance was not so strongly affected. Addition of $10 \mu \mathrm{M} \mathrm{Zn}$ (II) partially restored fitness of the multiple deletion strains up to $\Delta 7$. 


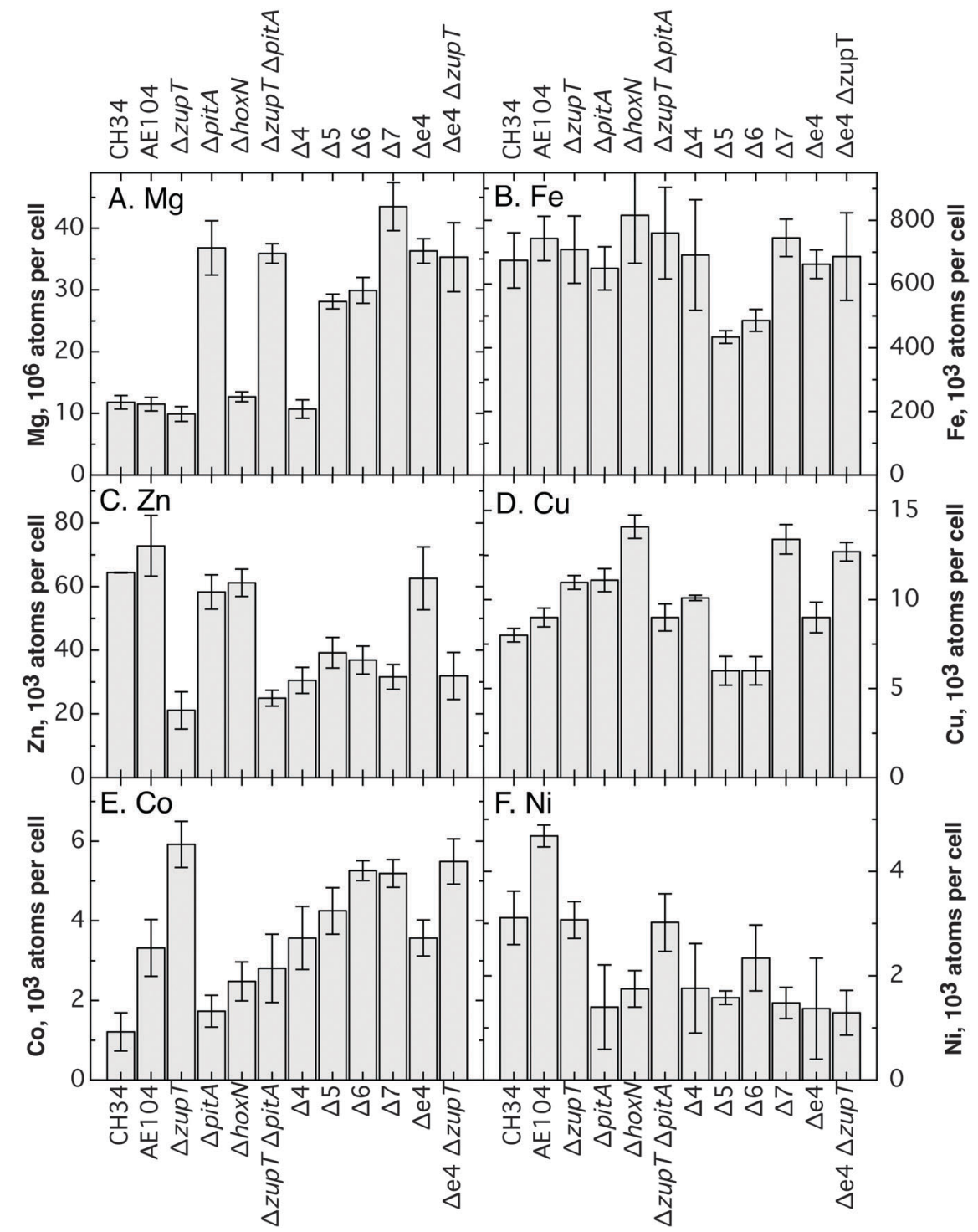

Fig. 2 Metal content of C. metallidurans strains. As determined by ICP-MS. The data are also shown in Table S1 (ESI†).

The mutant cells were cultivated in the presence of higher concentrations of transition metals in liquid TMM in doseresponse experiments and the $\mathrm{IC}_{50}$ values were calculated (Fig. 3 and Table S3, ESI $\dagger$ ). These experiments (up to $20 \mathrm{~h}$ ) revealed more effectively the differences in metal resistance between the mutant strains than the long-term (up to 3 days) MIC determinations. Zinc, cobalt and cadmium resistance of the $\Delta z u p T$ strain was decreased compared to the parent strain, and that of the $\Delta 7$ strain was decreased compared to $\Delta z u p T$ (Fig. 3).

During the course of the deletion analysis it was observed that zinc resistance decreased in series from the parent strain AE104 to the $\Delta z u p T$ and to the $\Delta p i t A$ mutants (Fig. 3A). In the case of the $\Delta z u p T \Delta$ pitA mutant resistance remained at the $\triangle z u p T$ level and increased to the level of the parent strain again in $\Delta 4\left(\Delta z u p T \Delta \operatorname{corA}_{123}\right)$. Decreased zinc resistance in the $\Delta p i t A$ mutant strain was mediated partially by ZupT and decreased zinc resistance in the $\Delta z u p T$ strain by $\mathrm{CorA}_{123}$. Zinc resistance of the $\Delta 5$ strain ( $\left.\Delta z u p T \Delta p i t A \Delta c o r A_{123}\right)$ was similar to that of the $\Delta p i t A$ strain demonstrating that the interplay between these uptake systems, which substituted for each other, and the efflux systems was required for resistance to upper $\mu \mathrm{M} \mathrm{Zn}$ (II) concentrations. Deletion of $z n t B$ in $\Delta 5$ generating $\Delta 6$ increased zinc resistance again. ZntB was partially responsible for the low zinc resistance level of the $\Delta 5$ strain, although this deletion did not change the zinc content of TMM-grown cells (Fig. 2C), Zinc resistance finally decreased to the lowest level in the $\Delta 7$ strain following deletion of hoxN, probably due to use of additional unknown zinc uptake systems that were not in balance with the efflux systems. This demonstrated that all seven systems were involved in zinc homeostasis, either as probable zinc importers $\left(\mathrm{CorA}_{123}\right.$ in $\Delta z u p T$, ZntB in $\left.\Delta 5\right)$ or by interfering with activation of other uptake routes.

A second series of deletion mutants in the order $\Delta$ hox $N \rightarrow$ $\Delta z u p T \rightarrow \Delta z n t B \rightarrow \Delta$ pitA also demonstrated this order of decreasing zinc resistance (Fig. 3A). Zinc resistance decreased 


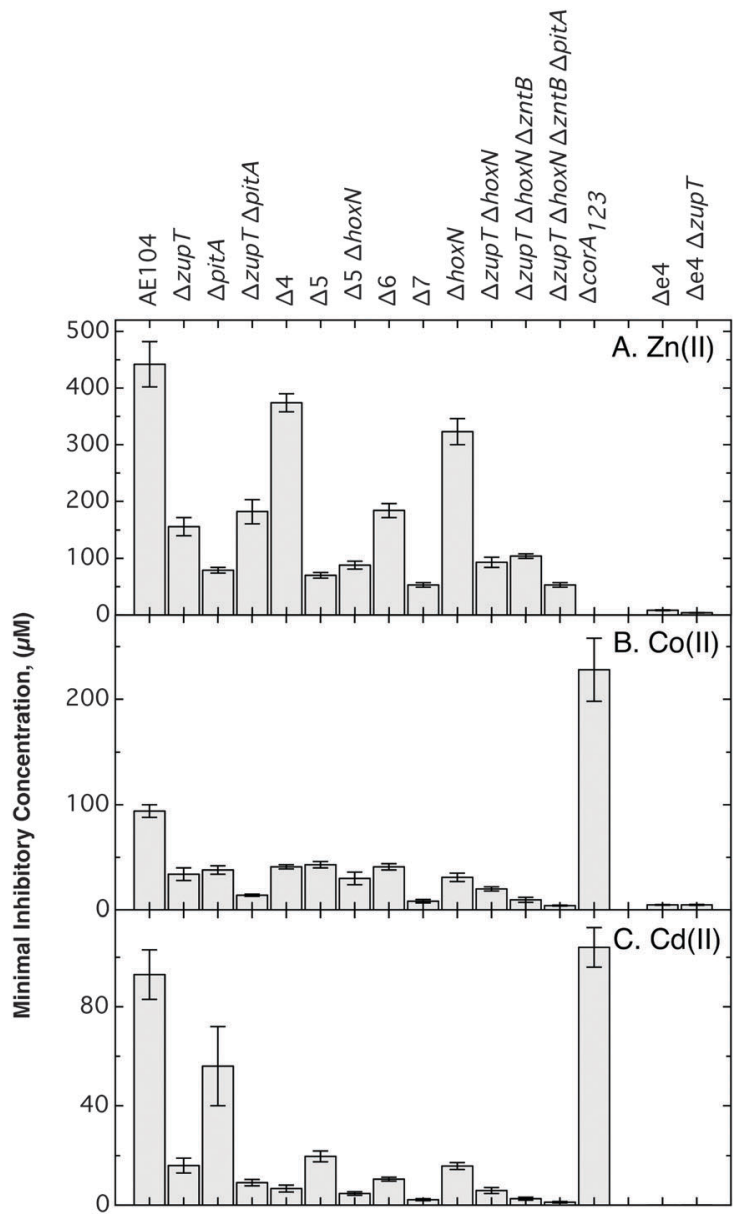

Fig. 3 Metal resistance of deletion strains in liquid culture. Dose response experiments were performed ( $n>3$ per conditions) in the presence of Zn(॥) (panel A), Co(॥) (panel B) and $\mathrm{Cd}(॥)$ (panel C), and the $\mathrm{IC}_{50}$ values calculated. The data are also shown in Table S3 (ESI $\dagger$ ) for a better documentation of the differences in cobalt and cadmium resistance of the mutant strains.

in this order except when zntB was deleted in the $\Delta z u p T \Delta h o x N$ double mutant. The presence of ZntB was not required when PitA and $\mathrm{CorA}_{123}$ were still present, and it was recruited only in the $\Delta 5$ strain. These results also defined a ranking order of the zinc importers: first, PitA because $\Delta p i t A$ had the strongest effect on zinc resistance and zinc resistance of $\Delta 4$ was close to that of the parent strain AE104; second, ZupT because of the required supply of zinc to zinc-dependent proteins; third, CorA $_{123}$ which was partially responsible for zinc sensitivity of the $\Delta z u p T$ strain; fourth, ZntB as metal importer in $\Delta 5$; and finally HoxN.

Additionally, cobalt and cadmium resistance decreased with each step along the second deletion series. With one exception, resistance to cadmium also decreased along the first deletion series (Fig. 3B, C and Fig. S3 (ESI $\dagger$ ), upper part): it increased about three-fold when pitA was deleted from the $\Delta 4$ strain leading to $\Delta 5$ so that PitA was responsible for cadmium imbalance in the $\Delta 4$ strain, indicating that PitA also imported cadmium:phosphate.

Cobalt resistance was especially low in the $\Delta z u p T \Delta$ pitA double mutant and increased again when the corAs were deleted.
Similar to what was observed with the experiments on solid TMM, the three CorAs seemed to be important cobalt uptake systems. In agreement with this, cobalt resistance of the $\Delta c o r A_{123}$ triple mutant was twice as high in liquid culture as that of the parent strain AE104 (Fig. 3B).

Since the cobalt resistance level of most mutant strains was so surprisingly low, resistance of the uptake mutants was also compared to that of the quadruple efflux deletion mutant $\Delta \mathrm{e} 4$

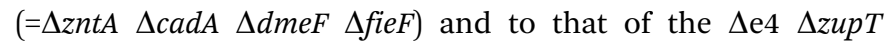
mutant (Fig. 3). The $\mathrm{IC}_{50}$ of $\Delta \mathrm{e} 4$ for zinc was only $8 \mu \mathrm{M}$, much lower than that of the $\Delta 7$ mutant which had an $\mathrm{IC}_{50}$ of $53 \mu \mathrm{M}$. Deletion of zupT always decreased zinc resistance down to $1 / 2$ or $1 / 3$, in the AE104 background from $440 \mu \mathrm{M}$ to $156 \mu \mathrm{M}$, in the $\Delta$ hoxN background from $323 \mu \mathrm{M}$ to $93 \mu \mathrm{M}$, and in the $\Delta \mathrm{e} 4$ background from 8.3 to $3.9 \mu \mathrm{M}$. This occurred despite the fact that the cellular zinc content decreased (Fig. 2) and addition of zinc ameliorated the retarded growth of the $\Delta z u p T$ mutant strain (Fig. 1). Because the CorAs were responsible for the decreased zinc resistance in the $\Delta z u p T$ single mutant (Fig. 3), the cells were able to partially compensate for the loss of ZupT by use of the CorAs, which led to imbalanced zinc import that could not be compensated by the metal efflux systems.

Cobalt resistance of the $\Delta \mathrm{e} 4, \Delta \mathrm{e} 4 \Delta z u p T$ and of the $\Delta z u p T$ $\Delta h o x N \Delta z n t B \Delta$ pitA quadruple mutant was similar with an $\mathrm{IC}_{50}$ of 4 to $5 \mu \mathrm{M} \mathrm{Co(II).} \mathrm{It} \mathrm{doubled} \mathrm{when} \mathrm{the} \mathrm{corAs} \mathrm{were} \mathrm{deleted} \mathrm{in}$ the quadruple mutant, leading to $\Delta 7$ (Fig. 3 and Table S3, ESI $\dagger$ ). Again, balanced import was required to allow efficient export. Cadmium resistance of the $\Delta \mathrm{e} 4$ mutant was 60 -times lower that that of the most sensitive $\Delta z u p T \Delta h o x N \Delta z n t B \Delta p i t$ q quadruple mutant showing the greater importance of the efflux systems compared to the uptake systems in resistance to this "toxic-only" metal cation. A balanced metal import and export was important for the "essential-but-also-toxic" metals but efflux was the main contributor to resistance to the "toxic-only" cadmium cation.

The $\Delta 7$ strain also displayed decreased resistance to copper, gold and nickel compared to strain AE104 (Fig. 4). While copper resistance of the $\Delta z u p T, \Delta 5$ and $\Delta 6$ strains was on the same level in-between $\Delta 7$ and AE104, nickel resistance increased from $\Delta z u p T$ to $\Delta 5$ and $\Delta 6$, and decreased again from $\Delta 6$ to $\Delta 7$ as a result of the deletion of the nickel importer HoxN. Gold resistance of all mutant strains was similar and lower than that of the parent strain AE104 (Fig. 4). Resistance to the metalcomplexing component EDTA decreased due to the $\Delta z u p T$ deletion in the AE104 parent strain and in the $\Delta$ e 4 efflux mutant. Here, in the absence of efflux systems, EDTA resistance was 5-times higher than in AE104 (Fig. 4).

When oxidative stress resistance of the mutant strains was examined as a marker of general stress tolerance (Fig. 5), $\Delta 7$ was as resistant to $\mathrm{H}_{2} \mathrm{O}_{2}$ and paraquat as the $\Delta z u p T$ mutant. The $\Delta$ pitA and $\Delta \mathrm{e} 4$ strains demonstrated a higher paraquat, but not $\mathrm{H}_{2} \mathrm{O}_{2}$, resistance compared to the parent strain, which was decreased again by additional deletion of zupT ${ }^{22}$ This demonstrates further the importance of ZupT for oxidative stress resistance.

These data clearly demonstrate that the interaction between metal uptake and efflux systems, and not only the activity of the 


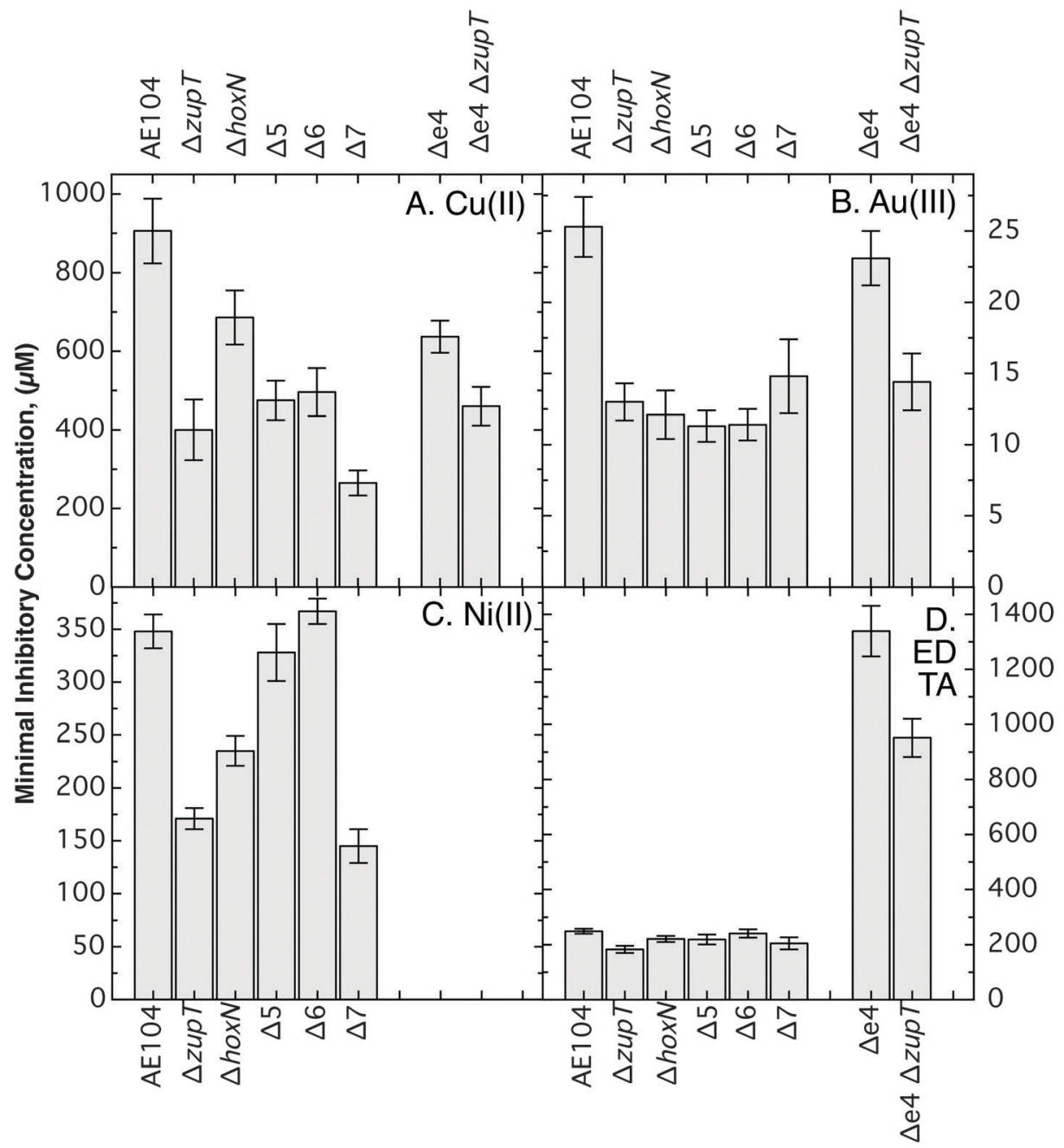

Fig. 4 Metal resistance of deletion strains in liquid culture. Dose response experiments were performed ( $n>3$ per conditions) in the presence of Cu(II) (panel A), Au(III) (panel B), Ni(I) (panel C) and EDTA (panel D), and the IC 50 values calculated. Bold-faced values indicate significant deviations from metal resistance of the direct parent strain. The data are also shown in Table S4 (ESI $\dagger$ ) for a better visibility of the differences between the strains.

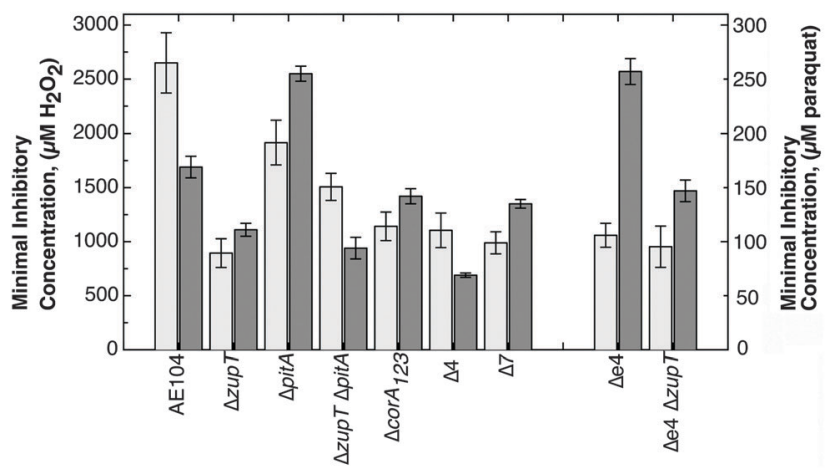

Fig. 5 Oxidative stress resistance of deletion strains in liquid culture. Dose-response experiments were performed ( $n>3$ per conditions) with $\mathrm{H}_{2} \mathrm{O}_{2}$ (light grey bars) and paraquat (dark grey bars), and the $\mathrm{IC}_{50}$ values calculated. The data are also shown in Table S5 (ESI†).

uptake systems, is responsible for a balanced supply of "essentialbut-also-toxic" metals to C. metallidurans. Deletion of zupT resulted in decreased fitness of the mutant and use of other metal import systems, which subsequently resulted in imbalanced metal import and decreased overall metal resistance. PitA was involved in homeostasis of all metals tested, while the three CorAs were required for cobalt and nickel homeostasis but they were also responsible for the decreased zinc sensitivity of the $\Delta z u p T$ mutant. Up to the $\Delta 5$ and $\Delta 6$ mutant, the fitness level of the mutant strains could be kept at that of the $\Delta z u p T$ mutant but at the cost of increasing problems in handling higher $(\mu \mathrm{M})$ concentrations of metals. This was first accomplished by PitA and the CorAs complementing loss of ZupT, subsequently the action of ZntB that was responsible for the low zinc resistance of the $\Delta 5$ strain, and finally of HoxN. When all seven systems were inactivated, overall fitness and metal resistance reached a low level, despite the presence of the metal efflux systems.

\section{Regulation of expression of the genes for the secondary uptake systems}

As published ${ }^{13}$ expression of a zupT-lacZ reporter gene fusion was up-regulated under zinc starvation conditions, that of $\operatorname{corA}_{1}$ lac $Z$ was down-regulated by increasing magnesium concentrations 
and that of pitA-lacZ by increasing phosphate concentrations. During the strategic construction of the deletion series, the lac $Z$ gene was inserted downstream of all seven transporter genes mentioned in this study, always leaving the open reading frame of the transporter gene intact. These fusions were constructed in strain AE104 and several mutant strains, and regulation of expression of the reporter gene by divalent transition metal cations and EDTA was measured. With three exceptions, this did not yield any insights or differences in the regulatory patterns between the strains (data not shown). Exception 1 was the already known global down-regulation of most genes by increasing zinc concentrations, as published. ${ }^{13}$

Exception 2 concerned expression of zntB-lacZ, which was introduced into AE104, $\Delta z u p T, \Delta 5$ (Fig. 6) and $\Delta p i t A$ (data not shown). In all these mutants, addition of zinc chloride up to $1 \mathrm{mM} \mathrm{Zn}$ (II) decreased expression of the reporter construct by half. Addition of cadmium at $0.5 \mathrm{mM} \mathrm{Cd(II)} \mathrm{decreased} \mathrm{zntB-lacZ}$ expression down to $25 \%$ of the value without added metals. No difference was visible in zntB-lacZ expression between the AE104, $\Delta z u p T$ and $\Delta 5$ derivatives (Fig. 6). EDTA, Co(II), or Mn(II) had no effect but $\mathrm{Cu}$ (II) also resulted in a down-regulation of $z n t B-l a c Z$ expression (data not shown). Decreased expression at the high metal cation concentrations could also result from metal toxicity in addition to the metal-dependent changes. ZntB was regulated as would be expected for an uptake system, and was down-regulated when high concentrations of thiolbinding metals such as cadmium and copper were challenging the cells. Regulation was independent of the presence of ZupT, PitA or CorA $_{123}$. Although $\mathrm{ZntB}$ was involved in the low zinc resistance level of the $\Delta 5$ strain, its gene was not up-regulated, nor in the double, triple or quadruple mutants tested. As the altered cellular metal content and metal resistance indicated that ZntB, the CorAs and PitA were subsequently used in the respective mutant strains, activation may have been on various levels, e.g. the translational level, by flux control or other posttranscriptional mechanisms in addition to the already published changes in zupT and pitA expression. ${ }^{13,17}$ This indicated a crosstalk between PitA, ZupT, CorA $\mathrm{A}_{123}$ and ZntB, which organized metal import into $C$. metallidurans cells and was flexible enough to compensate for loss of some of these proteins, albeit not at higher metal concentrations.

The third exception was revealed by the hoxN-lacZ expression pattern (Fig. 6B): the gene was not regulated by EDTA, nickel or cobalt in all tested strains (data not shown), and was not regulated by zinc in strain AE104 (Fig. 6B), staying at a low specific activity of $9.4 \pm 2.7 \mathrm{U} \mathrm{mg}^{-1}$ dry mass. In $\Delta z u p T$ and $\Delta 5$, hoxN-lacZ was expressed on a low level but 2-fold up-regulated with increasing zinc concentrations up to $1 \mathrm{mM}$. Surprisingly, the operon fusion was strongly expressed in the $\Delta 6$ strain at $81 \pm 5 \mathrm{U} \mathrm{mg}^{-1}$ and down-regulated 1.6-fold with increasing zinc concentrations (Fig. 6B). It is likely that HoxN was recruited for metal import but only in the $\Delta 6$ mutant when all other known secondary metal import systems were inactivated.

Although metal uptake systems were removed stepwise up to $\Delta 5$, the mutant cells remained at the fitness level of the $\Delta z u p T$ mutant by use of substitute importers, members or non-

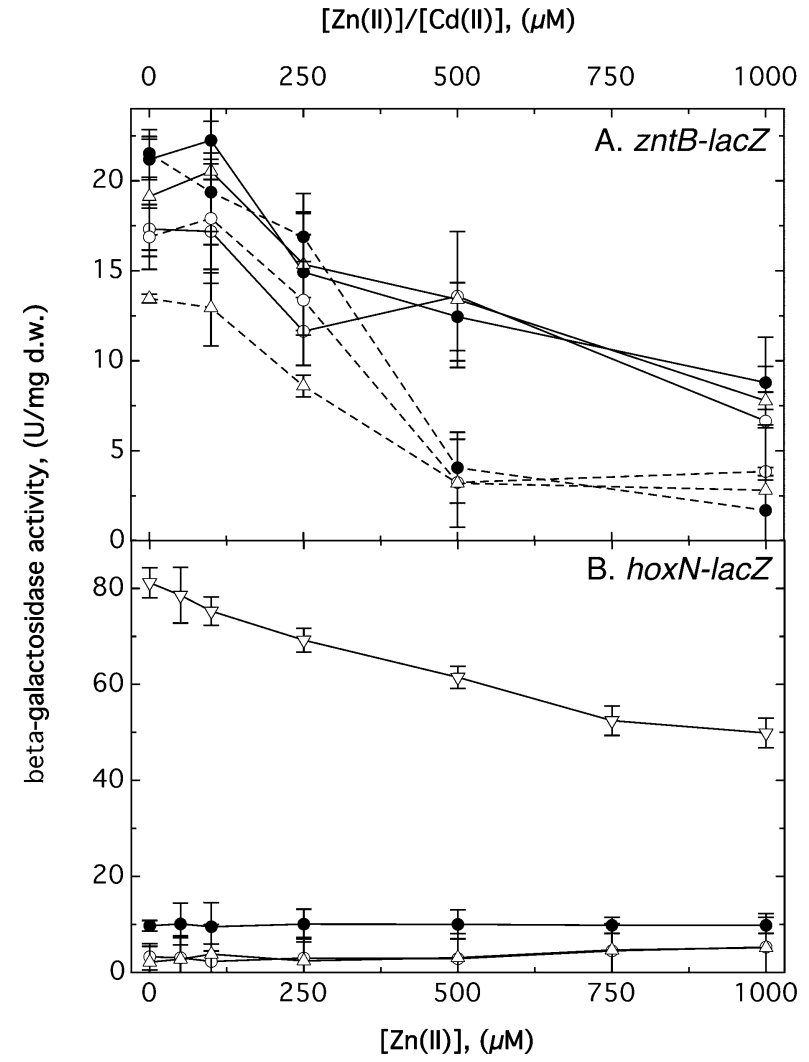

Fig. 6 Regulation of zntB- and hoxN-lacZ fusions in C. metallidurans. Exponentially growing cells of strain AE104 (closed circles, O), $\Delta z u p T$ (open circles, $\bigcirc$ ), $\Delta 5$ (open triangles, $\Delta$ ) or $\Delta 6$ (open inverted triangle, $\nabla$, only in panel B), all carrying a lacZ-fusion with the full-length zntB (panel A) or hoxN (panel B) gene, were divided into parallel cultures and zinc chloride (solid lines) or cadmium chloride (dashed lines) was added. Incubation was continued with shaking at $30{ }^{\circ} \mathrm{C}$ and the specific activity of the $\beta$-galactosidase was determined after $3 \mathrm{~h}$.

members of the group of seven studied transport systems, but metal resistance decreased along the series of deletion strains despite the presence of metal efflux systems. In $\Delta 6$, increased expression of hoxN was required for the strain to remain at the $\Delta z u p T$ fitness level. When hoxN was also gone, fitness and metal resistance decreased a second step to the level of the $\Delta 7$ mutant strain.

\section{Intracellular zinc homeostasis}

Deletion of zupT had two main effects: zinc could not be supplied efficiently to the zinc-dependent beta-prime subunit RpoC of the RNA polymerase, leading to accumulation of RpoC in inclusion bodies; and the central subunit CzcA of the CzcCBA transenvelope complex for cobalt, zinc, cadmium resistance could not be maintained in the cells although $c z c A$ was transcribed and constitutively expressed. ${ }^{21,22}$ Both effects were used here as reporters for the ability of the mutant strains to maintain their intracellular zinc homeostasis.

Deletion of zupT always resulted in loss of the CzcA band, which was visible in the parent strain AE104 and the $\Delta$ pitA single deletion strain (Fig. 7). This corresponded to a zinc content below 40000 atoms per cell (Fig. 2) in all these strains. 
The situation was more complicated concerning zinc allocation to RpoC. If this ability was disturbed, as in the $\Delta z u p T$ single mutant, RpoC protein was transferred to inclusion bodies and the RpoC band was very intense in the Coomassie-stained polyacrylamide gels after separation of crude extracts (Fig. 7A, lane 2). Surprisingly, and accompanied by a decrease of the cellular zinc content from 73000 to 58000 atoms per cell (Fig. 2), probably misfolded RpoC also accumulated in the $\Delta$ pitA strain (Fig. 7B, lane 3). In contrast, extracts of the $\Delta z u p T$ $\Delta$ pitA double and the $\Delta 4$ quadruple mutant did not display a strong RpoC band, indicating efficient zinc allocation. Starting with the $\Delta 5$ mutant, crude extracts of all subsequent strains exhibited a strong RpoC band $(\Delta 5$ and $\Delta 6$ in lanes 6 and 7 of Fig. 7A, $\Delta 7$ not shown). Allocation of zinc to RpoC was efficient in the parent strain AE104, hampered when ZupT or when PitA were removed, efficient again when only $\mathrm{CorA}_{123}$ or only PitA was present, and no longer efficient in the subsequent higher order deletion strains. This could mean some negative interference between PitA and $\mathrm{CorA}_{123}$ on the one hand and of ZupT and $\mathrm{CorA}_{123}$ on the other, which prevented zinc allocation in the $\Delta z u p T$ and $\Delta p i t A$ mutant, respectively. On the other hand, PitA or CorA $_{123}$ alone were able to substitute for ZupT when zinc allocation to RpoC was concerned, but their activity did not allow the stable presence of CzcA.

In agreement with a high cellular zinc content and resistance to EDTA, the $\Delta \mathrm{e} 4$ efflux mutant synthesized the CzcA protein and folded RpoC properly to prevent aggregation of this protein in inclusion bodies (Fig. 7, lanes 8). When zupT was deleted in $\Delta \mathrm{e} 4$ and the zinc content dropped to 32000 atoms per cell,

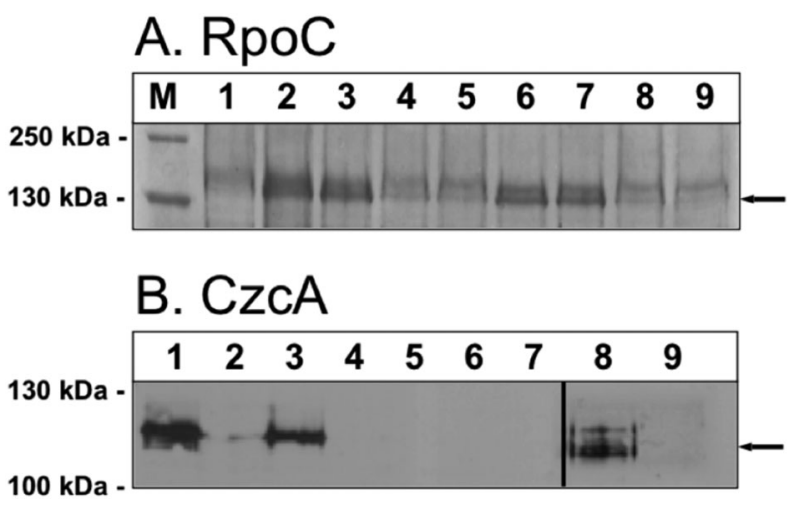

Fig. 7 Presence of RpoC and CzcA proteins in mutant strains of $C$. metallidurans AE104. Accumulation of the RpoC subunit of the RNA polymerase (panel A, arrow) was demonstrated in crude extracts in Coomassie-stained SDS gel. ${ }^{21}$ Samples corresponding to $20 \mu \mathrm{g}$ cellular dry mass was used per lane. Only the part of gel between the $130 \mathrm{kDa}$ and the $250 \mathrm{kDa}$ marker band is shown; the complete gels serving as loading control are shown in Fig. S2 (ESI $\dagger$ ). The plasmid pDNA130 ${ }^{26}$ that expressed the $C Z C C B A D^{\prime}$ determinant constitutively in $C$. metallidurans cells had been transferred by conjugation into the mutant strains and their ability to produce the CzcA (panel B, arrow) central component of the CzcCBA efflux pump was determined in a Western blot using anti-CzCA antibodies, as published. ${ }^{21}$ Marker (M); AE104 negative control (1); $\Delta z u p T$ positive control (2); $\Delta$ pitA (3); $\Delta$ zupT $\Delta$ pitA (4), $\Delta 4$ (5); $\Delta 5$ (6); $\Delta 6$ (7); $\Delta \mathrm{e} 4$ (8); $\Delta \mathrm{e} 4$ $\Delta z$ zup $(9)$. As indicated by the bar, the experiment shown in panel $B$ lanes 8 and 9 was on a different gel that that in B lanes 1 to 7 . zinc allocation to RpoC was still efficient (Fig. 7A, lane 9), indicating that the negative interference of PitA and CorA $_{123}$ did not occur in the $\Delta \mathrm{e} 4$ efflux mutant strain. The CzcA band was visible in Western blots of fresh cultures of the $\Delta \mathrm{e} 4 \Delta z u p T$ mutant strains (data not shown) but similar to the situation in strain AE104 and its $\Delta z u p T$ mutant, zinc resistance, as determined as $\mathrm{IC}_{50}$ values, decreased after more than 5 transfers on strain collection plates (Fig. S3, ESI $\dagger$ ) and CzcA was no longer present in the cells (Fig. 7B, lane 9). While other import pathways could complement for a missing ZupT importer when it comes to cytoplasmic zinc allocation, the long-term presence of CzcA strictly depended on the presence of ZupT if the cells were not kept on media with increased zinc content.

\section{Discussion}

Heavy metal resistance can be defined as the ability to maintain metal homeostasis in the presence of high concentrations of metals or metal mixtures. In C. metallidurans, the plasmidencoded RND-driven transenvelope systems such as CzcCBA and CnrCBA are responsible for the high resistance level to zinc and nickel, respectively. ${ }^{27-29}$ It is highly likely that efflux by these transenvelope protein complexes pre-adjusts the periplasmic metal content for subsequent uptake into the cytoplasm, or they transport metal ions to the outside that were previously exported from the cytoplasm to the periplasm by efflux systems of the inner membrane, ${ }^{5,6}$ such as P-type ATPases and CDF proteins. This demonstrates the importance of the metal transportome, ${ }^{30,31}$ the totality of all metal export and import systems, to metal resistance and homeostasis in $C$. metallidurans. The combined actions of metal uptake and efflux systems might result in a kinetic flow-equilibrium of the transition metal concentration in both cellular compartments, ${ }^{32}$ which adjusts individual concentrations and the composition of the overall mixture to prevent negative interference between "essential-but-also-toxic" metal cations such as $\mathrm{Zn}$ (II) and Ni(II).

E. coli does not possess CzcCBA- or CnrCBA-like efflux systems. ${ }^{33}$ In this gut bacterium, a controlled shunt of zinc import and export systems seems to be important for zinc homeostasis. Import is by a variety of systems with broad substrate specificity such as ZupT, ${ }^{18}$ complemented by the $\mathrm{ABC}$ transport system ZnuABC under zinc starvation conditions, ${ }^{14,15}$ or alternatively by ZntA-dependent export when the metal is in surplus. ${ }^{34-36}$ Expression of $z n u A B C$ is under control of the Zur regulator of the Fur family of proteins, ${ }^{15,37}$ that of $z n t A$ for the zinc-transporting $\mathrm{P}_{\mathrm{IB} 2}$-type ATPases regulated by the MerR member ZntR. ${ }^{38}$ While $z$ int expression is $50 \%$ up-regulated at about $1 \mathrm{fM}$ "free" zinc in the cytoplasm, that of $z n u A B C$ is $50 \%$ up-regulated at about $0.2 \mathrm{fM}$ "free" zinc, and both systems are below 25\% expression level at about $0.5 \mathrm{fM}^{39}$ This equilibrium concentration of zinc in E. coli corresponds to a quota of $0.2 \mathrm{mM}$ or 200000 atoms per cell and a ratio of $2.5 \times 10^{-12}$ between the zinc quota and "free" zinc. This can be explained by sequestration of $\mathrm{Zn}$ (II) in the cytoplasm by glutathione and zinc-binding proteins. ${ }^{22,40}$ This means that the distribution of $\mathrm{Zn}(\mathrm{II})$ between zinc-binding sites 
in ZntR, Zur and other proteins, e.g. those of the ribosome, ${ }^{41}$ may contribute to maintenance of the zinc homeostasis by activating alternatively zinc import by ZunABC or export by ZntA, so that this shunt controls the level of zinc in the cytoplasm of E. coli.

C. metallidurans cells contain a minimum of 20000 zinc per cell, with approximately 70000 when cultivated in TMM without added zinc. When zinc is added to the medium there are 120000 zinc per cell due to the action of the efflux systems, and the bacterium cannot grow when it harbors more than 250000 zinc per cell. ${ }^{21}$ This corresponds to a quota of $58 \mu \mathrm{M}$, $204 \mu \mathrm{M}, 350 \mu \mathrm{M}$ and $728 \mu \mathrm{M}$, respectively (assumed cell volume of $0.57 \mathrm{fL}^{42}$ ), so that the zinc quota of $E$. coli and C. metallidurans are similar. Unexpectedly, no evidence for a shunt was found in C. metallidurans. ${ }^{13}$ There is no ortholog in this bacterium for a ZnuABC uptake system but for a $\mathrm{ZntA}^{43}$ efflux pump. While expression of zupT in E. coli was constitutive, ${ }^{18}$ zupT in C. metallidurans was controlled by its Zur ortholog. ${ }^{13,17}$ A main substrate and a role in basic resistance or high-level resistance could be assigned to all efflux systems in C. metallidurans; ${ }^{7}$ however this could not be done with the studied secondary metal import systems. ${ }^{13}$ This led to the hypothesis that a battery of redundant importers with low and overlapping substrate specificities was responsible for uptake of zinc and other transition metals in $C$. metallidurans.

Here, further evidence was found to support this hypothesis. It appears that $C$. metallidurans takes $\mathrm{Zn}$ (II), Ni(II) and Co(II) up as they become available. It relies on its efflux systems to remove surplus ions. Using the plasmid-encoded CzcCBA and CnrCBA systems it pre-adjusts the periplasmic metal composition, as well as concentration, prior to uptake across the inner membrane. The plasmid-free C. metallidurans derivative $\mathrm{AE} 104^{27}$ is in this aspect an anomaly because it is not able to perform this periplasmic pre-adjustment but is forced to import zinc, cobalt, and nickel "as they come along", while E. coli escapes this situation by using the ZnuABC/ZntA shunt for zinc, and maybe a similar shunt (NikABC/RcnA) for nickel. ${ }^{44,45}$ This also explains why strain AE104 suffers from transition metal stress in the cytoplasm, resulting in silencing of genomic islands even in TMM without added metals. ${ }^{23}$ However, it was not possible to construct similar deletion mutants in $\mathrm{CH} 34$ wild type because even deletion of zupT efficiently cures the $c z c$-containing plasmid pMOL30, ${ }^{21}$ providing evidence that the interplay of metal uptake and efflux systems is important in C. metallidurans.

When the genes for the seven secondary uptake systems were deleted, the cells were able to compensate for some of the consequences of this, revealing flexibility of the metal uptake transportome. However if any other were removed no compensation was observe, pointing to unique and important contributions of individual systems. Removal of all seven importers did not impair the overall metal content of the cells (Fig. 2) so that additional metal uptake systems must exist. Up to the quintuple deletion mutant $(\Delta 5)$ lac $Z$ reporter gene fusions in various mutant strains did not show any up-regulation of the genes for the remaining uptake systems, nor was such a process evident on the transcriptome ${ }^{23}$ or proteome ${ }^{22}$ level of the $\Delta z u p T$ deletion strain, despite the obvious zinc starvation conditions this strain was experiencing. ${ }^{23}$ Only in the sextuple deletion mutant, $\Delta 6$, was an altered expression pattern of the hox $N$ gene measured (Fig. 6B). This was due to recruitment of the predicted nickel importer HoxN for import and to compensate for the loss of the other systems. With the exception of $\operatorname{HoxN}$, all the other known and unknown metal uptake systems were activated by means other than increased gene expression, such as flux control of, or protein-protein interaction with, already synthesized proteins. If this hypothesis is true, it would indicate the existence of a novel control mechanism of metal homeostasis in C. metallidurans.

Along the series of deletion mutants, the following observations were made: (i) deletion of zupT in the parent strain AE104 decreased fitness (Fig. 1); (ii) deletion of corA genes revealed an interplay of the CorA proteins (Table S2, ESI $\dagger$ ); (iii) deletion of pitA increased the cellular magnesium content (Fig. 2) and influenced homeostasis of, and resistance to, most transition metals tested (Fig. 3). Nevertheless, deletion of these five genes did not decrease fitness (Fig. 1), only metal resistance (Fig. 3), indicating that use of other known (e.g. ZntB) or unknown importers compensated for the loss of the deleted genes. This also resulted in unbalanced metal import at $\mu \mathrm{M}$ metal concentrations that could no longer be compensated for by the efflux systems. Loss of zntB needed increased hoxN expression (Fig. 6B) to keep the fitness at the level of the $\Delta z u p T$ strain (Fig. 1) but this was no longer possible in the $\Delta 7$ mutant (Fig. 1). Fitness and metal resistance dropped to a second, lower level (Fig. 1 and 3).

First, all these findings highlight the importance of ZupT among the other secondary metal uptake systems in C. metallidurans. ZupT was required in strain AE104 to allocate zinc to the client protein RpoC efficiently and this function could only partially be compensated for by an increased cellular zinc content in the $\Delta z u p T$ mutant. ${ }^{21}$ Zinc imported by ZupT was required to allow a stable presence of the RND protein CzcA or the CzcCBA zinc efflux complex. ${ }^{21}$ While ZupT was absolutely essential for the long-term presence of CzcA, PitA and the CorAs were able to mediate efficient allocation of zinc to RpoC, but only when the respective other importer was not present in the cell (Fig. 7). Moreover, this negative interference between PitA and the CorAs did not occur in the $\Delta z u p T$ mutant of the quadruple efflux mutant $\Delta \mathrm{e} 4$, which was able to fold RpoC efficiently but unable to harbor CzcA (Fig. 7). Replenishment of the zinc pool required for RpoC folding nevertheless was not sufficient to allow stable synthesis of CzcA. ${ }^{21}$ PitA and the CorAs must somehow interact, e.g. on the hypothetical post-translational control level of metal homeostasis in C. metallidurans.

Second, the three CorAs are able to provide $\mathrm{Zn}$ (II) to RpoC in the $\Delta z$ zuT $\Delta$ pitA mutant (Fig. 7). Moreover, $\operatorname{CorA}_{1}$ and CorA $_{2}$ are involved in nickel import. $\operatorname{CorA}_{1}$ and $\mathrm{CorA}_{3}$ have something to do with cobalt toxicity although CorA $_{123}$ together functioned as cobalt importers. TMM-grown $C$. metallidurans cells contain

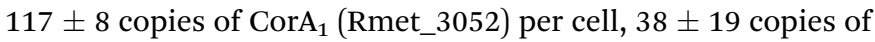
CorA $_{2}$ (Rmet_0036) and $37 \pm 5$ copies of CorA 3 (Rmet_3287), yielding a $3.2 \pm 0.2: 1.0 \pm 0.5: 1 \pm 0.1$ ratio of $\operatorname{CorA}_{1}: \operatorname{CorA}_{2}$ : $\mathrm{CorA}_{3} .{ }^{22}$ Since CorA-like proteins are pentamers, ${ }^{24}$ this could 
mean that the CorA of $C$. metallidurans is actually a $\left(\mathrm{CorA}_{1}\right)_{3^{-}}$ $\left(\operatorname{CorA}_{2}\right)_{1}\left(\operatorname{CorA}_{3}\right)_{1}$ heteromultimer. CorA is the primary magnesium channel in Salmonella ${ }^{46}$ and essential for virulence. ${ }^{47}$ Metal uptake in the archaeum Methanococcus jannaschii is in the order $\mathrm{Co}$ (II) $>\mathrm{Ni}$ (II) $>\mathrm{Mn}$ (II) $>\mathrm{Mg}$ (II) $>\mathrm{Ca}\left(\right.$ II). ${ }^{48} \mathrm{Co}$ (II) and $\mathrm{Ni}(\mathrm{II})$ - but not $\mathrm{Ca}$ (II) and $\mathrm{Fe}(\mathrm{II} / \mathrm{III})$ transport - was also demonstrated for a homolog from the plant Arabidopsis thaliana. ${ }^{49}$ In C. metallidurans, contribution of CorA $_{123}$ to cobalt, zinc, nickel, and cadmium import explains the metal-resistance phenotypes of the deletion mutants.

Import activity of CorA from T. maritima is under flux control. The pentameric complex is locked in a transport-incompetent conformation by allosteric, sequential binding of cytoplasmic $\mathrm{Mg}$ (II) cations to the five protomers. ${ }^{50}$ Because the amino acids required for transport and flux control by gating are all conserved within the MIT protein family, eukaryotic homologs included, this flux-controlled uptake of magnesium seems to be a general mechanism. ${ }^{51}$ This may indicate that the individual protomers of the possible heteromultimeric CorA $_{123}$ importer in C. metallidurans could be under different flux control regimes, $\operatorname{CorA}_{1}$ by $\mathrm{Mg}$ (II), $\operatorname{CorA}_{2}$ by $\mathrm{Ni}(\mathrm{II})$ and $\mathrm{CorA}_{3}$ by $\mathrm{Co}(\mathrm{II})$. These CorA substrates were identified already a long time ago in E. coli and Aerobacter (=Enterobacter) aerogenes, ${ }^{52}$ nickel uptake by a magnesium uptake system in Cupriavidus necator (=Ralstonia eutropha, Alcaligenes eutrophus) $)^{53}$ and C. metallidurans. ${ }^{32,54}$ Moreover, expression of $\operatorname{corA}_{1}$ is up-regulated 3 -fold under conditions of magnesium starvation while that of $\operatorname{corA}_{2}$ and of $\operatorname{corA}_{3}$ is slightly down-regulated, ${ }^{13}$ so that the complex may change from a homopentameric $\operatorname{CorA}_{1}$ under magnesium flux control at low (10 $\mu \mathrm{M})$ magnesium concentrations to a heteropentameric CorA $_{123}$ under combined magnesium, nickel and cobalt flux control at magnesium concentrations above $100 \mu \mathrm{M}$. Heteromultimers with different functions have also been described for other metal transporters ${ }^{25}$ so that this hypothesis should be tested.

Third, PitA was an important metal uptake system. In E. coli, PitA also seems to be involved in zinc uptake ${ }^{55}$ and some strains of this bacterium even contain a paralog of PitA, PitB. ${ }^{56}$ Consequently, mutations in pitA cause zinc resistance. ${ }^{57}$ PitA also imports phosphate complexes with magnesium and calcium, and Zn(II) competes with Mg(II) for import by PitA. ${ }^{57}$ This would be a very energy-efficient import route for essential micro- and macroelements. If, however, all 110 million phosphate molecules needed by $C$. metallidurans ${ }^{13}$ would be imported as metal:phosphate complexes by PitA, far too many metal cations would be imported into the cytoplasm, e.g. 76 million $\mathrm{Mg}$ (II) with 11 million actually needed. These surplus cations would have to be exported again.

As an alternative for energy-dependent efflux of surplus $\mathrm{Mg}$ (II) and $\mathrm{Ca}(\mathrm{II})$, metal:phosphate import by the low-affinity PitA transporter could be synchronized with phosphate import by the high-affinity ABC-type import system PstABC, which transports non-metallated $\mathrm{H}_{2} \mathrm{PO}_{4}{ }^{-}$and $\mathrm{HPO}_{4}{ }^{2-} \cdot{ }^{58,59}$ C. metallidurans contains 1700 copies of the periplasmic-binding component PstS. Its genome possesses genes for two additional paralogs of this protein, one synthesized in 100 copies per cell. ${ }^{22}$
This argues for a strong participation of PstABC in phosphate import in TMM-grown cells, which may have the role to prevent any over-accumulation of metal cations. This scenario agrees with the fact that PitA is up-regulated with increasing phosphate concentrations $^{13}$ starting at $100 \mu \mathrm{M}$ phosphate and reaching maximum expression at $5 \mathrm{mM}$ phosphate: at such a high phosphate concentration, use of the energy-efficient PitA system would be much more attractive than importing phosphate by the "expensive" PstACB pathway.

Last, there are also conflicting data concerning the 4th member of the MIT protein family in C. metallidurans, ZntB. In Salmonella, mutations in its $z n t B$ gene conferred decreased zinc and cadmium resistance and capacity for zinc efflux was demonstrated. ${ }^{60}$ The structure of $\mathrm{ZntB}$ is that of a pentameric funnel similar to CorA. ${ }^{61}$ In C. metallidurans, however, a zntBlac $Z$ fusion was down-regulated with increasing zinc and especially cadmium concentrations (Fig. 6). This regulatory pattern agrees more with that of an importer than with an exporter. The consequence of a $z n t B$ deletion, even from the genome of the $\Delta 5$ mutant with ZupT, PitA and $\mathrm{CorA}_{123}$ removed, was minor with the exception of a two-fold increase in zinc and cadmium resistance. This assigned to $\mathrm{ZntB}$ the role of a minor zinc and cadmium importer in C. metallidurans. Expression of a hoxN-lacZ fusion increased in the $\Delta 6$ strain compared to $\Delta 5$, indicating that additional deletion of $z n t B$ resulted in activation of the last known secondary import system with some potential in zinc import. Consequently, the $\Delta 6$ strain performed not much differently from the $\Delta z u p T$ single deletion strain, while the growth problems of the $\Delta 7(=\Delta 6 \Delta h o x B)$ were considerable.

\section{Experimental}

\section{Materials and methods}

Bacterial strains and growth conditions. Strains used for experiments were $C$. metallidurans $\mathrm{CH} 34$ wild type, its plasmidfree derivative strain $\mathrm{AE} 104,{ }^{27}$ and further derivatives of these strains Table 1 . Tris-buffered mineral salts medium ${ }^{27}$ containing $2 \mathrm{~g} \mathrm{~L}^{-1}$ sodium gluconate (TMM) was used to cultivate these strains aerobically with shaking at $30{ }^{\circ} \mathrm{C}$. Solid TMM contained $20 \mathrm{~g} \mathrm{~L}^{-1}$ agar. Analytical grade salts of metal chlorides or sodiumtetrachloroaurate(III) ( NaAuCl4) (Sigma-Aldrich, USA or Alfa Aesar, Germany) were used to prepare 0.1 or $1 \mathrm{M}$ stock solutions.

Genetic techniques. Standard molecular genetic techniques were used. ${ }^{28,62}$ For conjugal gene transfer, overnight cultures of donor strain $E$. coli $\mathrm{S} 17 / 1^{63}$ and of the C. metallidurans recipient strains grown at $30{ }^{\circ} \mathrm{C}$ in Tris-buffered medium were mixed (1:1) and plated onto nutrient broth agar. After $2 \mathrm{~d}$, the bacteria were suspended in TMM, diluted, and plated onto selective media as previously described. ${ }^{28}$ All primer pairs used were listed in Table S6 (ESI $\dagger$ ). Plasmid pECD1003 ${ }^{7}$ was used to construct deletion mutants. It is a derivate of plasmid pECD889 ${ }^{64}$ and therefore a derivative of plasmid pCM184. ${ }^{65}$ These plasmids harbor a kanamycin-resistance cassette flanked by loxP recognition sites. Plasmid pECD1003 additionally carries an exchange of $5 \mathrm{bp}$ at each loxP-site. Using these mutant lox 
sequences, multiple gene deletions within the same genome are possible without secondary recombination events. ${ }^{66,67}$

Deletion mutants. Fragments of 300 bp upstream and downstream of the target gene were amplified by PCR and cloned into vector pGEM T-Easy (Promega, Madison, Wisc., USA), further cloned into plasmid pECD1003, and sequenced. The resulting plasmids were used in a double-cross-over recombination in $C$. metallidurans strains to replace the respective target gene with the kanamycin resistance cassette, which was also subsequently deleted by transient introduction of cre

Table 1 Bacterial strains and plasmids

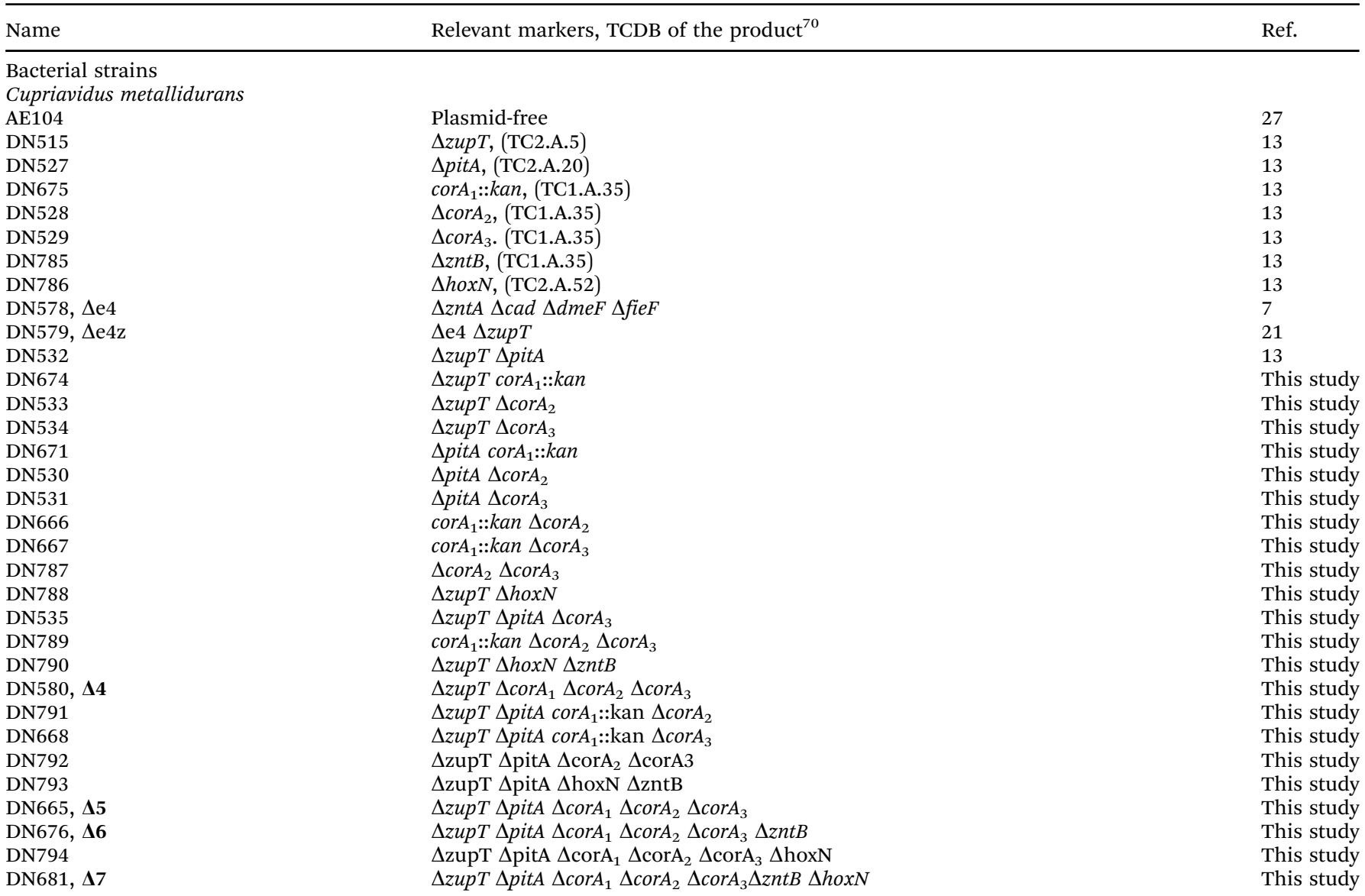

Conjugator strain

Escherichia coli

$\mathrm{S} 17 / 1$

Plasmids

lacZ, derivate of $\mathrm{pLO} 2$

pECD794-1

pECD1003

PVDZ2

pDNA130

pECD977

pECD981

pECD982

pECD983

pECD984

pECD1260

pECD1144

pECD1259

Contains Cre recombinase

Mutant lox sites, derivate of pECD889

Broad host range expression vector

pVDZ2:: $c z c C B A D^{\prime}$

pECD1003 construct for zupT deletion by cre-lox system pECD1003 construct for pitA deletion by cre-lox system pECD1003 construct for $c o r A_{1}$ deletion by cre-lox system pECD1003 construct for corA $_{2}$ deletion by cre-lox system pECD1003 construct for corA $_{3}$ deletion by cre-lox system pECD1003 constr. for zntB deletion by cre-lox system pECD1003 constr. for hoxN del. by cre-lox system pECD794 constr. for $\operatorname{corA}_{1}$ disruption pECD794 constr. for zupT LacZ reportergene pECD794 constr. for pitA LacZ reportergene

pECD986

pECD988

pECD989

pECD990

pECD1486

pECD1487

pECD1490

pECD1491 pECD794 constr. for $\operatorname{corA}_{1}$ LacZ reportergene pECD794 constr. for $\operatorname{corA}_{2}$ LacZ reportergene pECD794 constr. for $\operatorname{corA}_{3}$ LacZ reportergene pECD794 constr. for $z n t B$ LacZ reportergene pECD794 constr. for hoxN LacZ reportergene pECD794 constr. for $r p o B ~ L a c Z$ reportergene pECD794 constr. for Enolase LacZ reportergene 65 7 71 26 13 
expression plasmid pCM157. ${ }^{65}$ Cre recombinase is a site-specific recombinase from the phage $\mathrm{P} 1$ that catalyzes the in vivo excision of the kanamycin resistance cassette at the loxP recognition sites. The correct deletions of the respective transporter genes were verified by Southern DNA-DNA hybridization. For construction of multiple deletion strains, these steps were repeated. The resulting mutants carried a small open reading frame instead of the wild type gene to prevent polar effects. For gene disruption experiments, only the first step was performed.

Minimal inhibitory concentration. The MIC was determined in triplicate as the lowest concentration inhibiting bacterial growth on solid TMM. A pre-culture was incubated at $30{ }^{\circ} \mathrm{C}$ and shaken at $250 \mathrm{rpm}$ up to early stationary phase, then diluted 1:20 in fresh medium and incubated for $24 \mathrm{~h}$ at $30 \mathrm{C}$ and $250 \mathrm{rpm}$. This $24 \mathrm{~h}$ culture was diluted $1: 100$ in fresh medium and used for streaking onto plates containing different concentration of the respective metal salts. The plates were incubated at $30{ }^{\circ} \mathrm{C}$ for 3 days and cell growth was monitored.

Dose-response growth curves in 96-well plates. These were also conducted in TMM. A pre-culture was incubated at $30{ }^{\circ} \mathrm{C}$, $250 \mathrm{rpm}$ up to early stationary phase, then diluted $1: 20$ in fresh medium and incubated for $24 \mathrm{~h}$ at $30{ }^{\circ} \mathrm{C}$ and $250 \mathrm{rpm}$. Overnight cultures were used to inoculate parallel cultures with increasing metal concentrations in 96-well plates (Greiner). Cells were cultivated for $20 \mathrm{~h}$ at $30{ }^{\circ} \mathrm{C}$ and $1300 \mathrm{rpm}$ in a neoLab Shaker DTS-2 (neoLab, Heidelberg, Germany) and the optical density was determined at $500 \mathrm{~nm}$ or $600 \mathrm{~nm}$ as indicated in a TECAN infinite 200 PRO reader (TECAN, Männersdorf, Switzerland). To calculate the $\mathrm{IC}_{50}$ value (metal concentration that led to turbidity reduction by half) and the corresponding $b$-value (measure of the slope of the sigmoidal dose-response curve), the data were adapted to the formula $\mathrm{OD}(c)=\mathrm{OD} 0 /\{1+\exp ((c-\mathrm{IC} 50) / b)\}$, which is a simplified version of a Hill-type equation as introduced by Pace and Scholtz (1997) $)^{68}$ as published. ${ }^{69} \mathrm{OD}(c)$ is the turbidity at a given metal concentration; OD0, that at no added metal and $c$ the metal concentration.

$\beta$-Galactosidase assay and lacZ-reporter constructions. C. metallidurans cells with a lacZ reporter gene fusion were cultivated as a pre-culture in TMM containing $1.5 \mathrm{mg} \mathrm{L^{-1 }}$ kanamycin at $30{ }^{\circ} \mathrm{C}, 250 \mathrm{rpm}$ up to early stationary phase, then diluted into fresh medium with a cell density of 30 Klett units and incubated at $30{ }^{\circ} \mathrm{C}$. At a cell density of 60 to $70 \mathrm{Klett}$ units, metal salts were added in different concentrations and cells were incubated with shaking for a further $3 \mathrm{~h}$. The specific betagalactosidase activity was determined in permeabilized cells as previously published with $1 \mathrm{U}$ defined as the activity forming $1 \mathrm{nmol}$ of $o$-nitrophenol $\mathrm{min}^{-1}$ at $30{ }^{\circ} \mathrm{C}^{72}$ The lacZ reporter gene was inserted within (disruption) or downstream of the gene after the stop-codon (lacZ fusion) of several target genes to construct reporter operon fusions. This was done by single crossover recombination in C. metallidurans strains. A 300-400 bp PCR-product of the $3^{\prime}$ end or in the middle region of the target genes was amplified from total DNA of strain AE104 and the resulting fragments were cloned into plasmid pECD794-1 (pLO2-lacZ). ${ }^{7}$ All primer pairs used are listed in Table S6 (ESI $\dagger$ ).
The respective operon fusion cassettes were inserted into the open reading frame of the target gene by conjugation and single cross-over recombination.

SDS-PAGE and Western blot. Cells were cultivated under various conditions and the cell density was determined from the turbidity with an equilibration curve. A sample representing a dry weight of $20 \mathrm{mg}$ was mixed $1: 1$ with cracking buffer (final concentrations $125 \mathrm{mM}$ Tris- $\mathrm{HCl}$, pH 6.8, $20 \mathrm{~g} \mathrm{~L}^{-1} \mathrm{SDS} ; 0.5 \%$ (vol/vol) $\beta$-mercaptoethanol, $0.01 \mathrm{~g} \mathrm{~L}^{-1}$ bromophenol blue, $50 \%$ (vol/vol) glycerol), incubated for $30 \mathrm{~min}$ at $50{ }^{\circ} \mathrm{C}$ and loaded onto a SDS gel. ${ }^{73}$ The gel was stained with Coomassie Brilliant Blue or blotted (Trans-Blot, BioRad) onto a nitrocellulose membrane, dried by air and then blocked in PBS (4 mM $\left.\mathrm{KH}_{2} \mathrm{PO}_{4}, 16 \mathrm{mM} \mathrm{Na} \mathrm{HPO}_{4}, 115 \mathrm{mM} \mathrm{NaCl}\right), 5 \mathrm{~mL}$ Tween20 and $50 \mathrm{~g}$ skimmed milk per $\mathrm{l}$ with shaking at $23{ }^{\circ} \mathrm{C}$ for $16 \mathrm{~h}$. The membrane was washed 3 times for 5 min with PBS-Tween (PBS, $1 \mathrm{~mL}$ Tween $20 \mathrm{~L}^{-1}$ ) at $23^{\circ} \mathrm{C}$. The membrane was incubated for $1 \mathrm{~h}$ at $23{ }^{\circ} \mathrm{C}$ with shaking with the first antibody \{polyclonal CzcA-antibody 1:15 000, diluted in PBS-Tween, antibody raised in rabbits after CzcA purification $\left.{ }^{74}\right\}$. The membrane was washed three times for $5 \mathrm{~min}$ with PBS-Tween and twice for $5 \mathrm{~min}$ with PBS, incubated with the second antibody a monoclonal antirabbit-IgG conjugated with horseradish peroxidase (SigmaAldrich) diluted 1:50000 in PBS-Tween $\}$ for $1 \mathrm{~h}$ at $23{ }^{\circ} \mathrm{C}$ with shaking. Unbound antibody was washed off the membrane 3 times for $5 \mathrm{~min}$ with PBS-Tween and once for $5 \mathrm{~min}$ with PBS. For detection, the membrane was incubated with $5 \mathrm{~mL}$ solution 1 \{10 mM TrisHCl (pH 8.0), $150 \mathrm{mM} \mathrm{NaCl,} 0.4 \mathrm{mM}$ p-coumaric acid, $0.25 \mathrm{mM}$ luminol $\}$ and $5 \mathrm{~mL}$ solution $2\{10 \mathrm{mM}$ TrisHCl ( $\mathrm{pH}$ 8.0), $\left.150 \mathrm{mM} \mathrm{NaCl}, 5.4 \mathrm{M} \mathrm{H}_{2} \mathrm{O}_{2}\right\}$ for $1 \mathrm{~min}$. The excess liquid was wiped off and the membrane was exposed for $5 \mathrm{~s}$ to 5-15 min to chemo-luminescence detection film (Roche).

ICP-MS analysis. To determine the metal content, cells were cultivated up to 100 Klett units in TMM and the different metal salts or EDTA was added. When the cells had reached the middle of the exponential phase of growth at 150 Klett units, $10 \mathrm{~mL}$ cell suspension were centrifuged for $30 \mathrm{~min}$ at $4500 \times g$. Cells were washed twice with $50 \mathrm{mM}$ Tris-HCl buffer containing $10 \mathrm{mM}$ EDTA ( $\mathrm{pH} 7)$. The supernatant was discarded and the residual liquid carefully removed at each step. The pellet was suspended in concentrated $67 \%$ (wt/vol) $\mathrm{HNO}_{3}$ (trace metal grade; Normatom/PROLABO) and mineralized at $70{ }^{\circ} \mathrm{C}$ for $2 \mathrm{~h}$. Samples were diluted to a final concentration of $2 \%$ (wt $/ \mathrm{vol}$ ) nitric acid. Indium was added as internal standard at a final concentration of $10 \mathrm{ppb}$. Elemental analysis was performed via inductively coupled plasma mass spectrometry (ICP-MS) using ESI-sampler SC-2 (Elemental Scientific, Inc., Omaha) and an X-Series II ICP-MS instrument (Thermo Fisher Scientific, Bremen) operating with a collision cell and flow rates of $5 \mathrm{~mL} \times \mathrm{min}^{-1}$ of $\mathrm{He} / \mathrm{H}_{2}(93 \% / 7 \%)$, with an Ar carrier flow rate of $0.76 \mathrm{~L} \times \mathrm{min}^{-1}$ and an $\mathrm{Ar}$ make-up flow rate at $15 \mathrm{~L} \times \mathrm{min}^{-1}$. An external calibration curve was recorded with ICP-multi-element standard solution XVI (Merck) in 2\% (v/v) nitric acid. The sample was introduced via a peristaltic pump and analyzed for its metal content. For blank measurement and quality/quantity thresholds, calculations based on DIN32645 TMM were used. The results 
were transformed from ppm, ppb or ppt via molar units into atoms per sample and divided by the number of cells per sample, which had been determined before as colony-forming units.

\section{Conclusions}

The seven secondary metal uptake systems characterized in this study appear to communicate to form the core of the metal transportome $\mathrm{e}^{30,31}$ of C. metallidurans AE104 by an interplay with the four metal efflux systems ZntA, CadA, DmeF and FieF. This is supported by a remarkable similarity of the metal content and cobalt resistance, a feature severely affected by deletion of metal import genes, of the $\Delta 7$ metal uptake and the $\Delta \mathrm{e} 4$ efflux mutant. Since $\Delta 7$ is to some degree still able to maintain its cellular metal composition, more metal uptake systems must exist in $C$. metallidurans beyond the seven secondary importers. Up to $\Delta 6$, the plasticity of the metal uptake transportome revealed here seems not to involve increased gene expression for substitute importers but rather post-transcriptional events take over. Taken together with the disappearance of CzcA in zupT mutants, an important post-transcriptional level of control of the metal transportome seems to exist in C. metallidurans.

\section{Acknowledgements}

Funding for this work was provided by the Deutsche Forschungsgemeinschaft (Ni262/10). We thank Grit Schleuder for skilful technical assistance and Gary Sawers for helpful comments.

\section{Notes and references}

1 P. J. Janssen, R. Van Houdt, H. Moors, P. Monsieurs, N. Morin, A. Michaux, M. A. Benotmane, N. Leys, T. Vallaeys, A. Lapidus, S. Monchy, C. Medigue, S. Taghavi, S. McCorkle, J. Dunn, D. van der Lelie and M. Mergeay, PLoS One, 2010, 5, e10433.

2 L. Diels and M. Mergeay, Appl. Environ. Microbiol., 1990, 56, 1485-1491.

3 F. Reith, S. L. Rogers, D. C. McPhail and D. Webb, Science, 2006, 313, 233-236.

4 C. Dressler, U. Kües, D. H. Nies and B. Friedrich, Appl. Environ. Microbiol., 1991, 57, 3079-3085.

5 D. H. Nies, in Molecular Microbiology of Heavy Metals, ed. D. H. Nies and S. Silver, Springer-Verlag, Berlin, 2007, vol. 6, pp. 118-142.

6 D. H. Nies, in Microbial Efflux Pumps: Current Research, ed. E. W. Yu, Q. Zhang and M. H. Brown, Caister Academic Press, Norfolk, UK, 2013, pp. 79-122.

7 J. Scherer and D. H. Nies, Mol. Microbiol., 2009, 73, 601-621. 8 W. Busch and M. H. J. Saier, Crit. Rev. Biochem. Mol. Biol., 2002, 37, 287-337.

9 H. Nikaido and M. H. Saier, Jr., Science, 1992, 258, 936-942. 10 M. H. J. Saier, C. V. Tran and R. D. Barabote, Nucleic Acids Res., 2006, 34, D181-D186.
11 T. von Rozycki and D. H. Nies, Antonie van Leeuwenhoek, 2009, 96, 115-139.

12 T. von Rozycki, D. H. Nies and M. H. J. Saier, Comp. Funct. Genomics, 2005, 6, 17-56.

13 A. Kirsten, M. Herzberg, A. Voigt, J. Seravalli, G. Grass, J. Scherer and D. H. Nies, J. Bacteriol., 2011, 193, 4652-4663.

14 S. I. Patzer and K. Hantke, Mol. Microbiol., 1998, 28, 1199-1210.

15 S. I. Patzer and K. Hantke, J. Biol. Chem., 2000, 275, 24321-24332.

16 C. Navarro, L. F. Wu and M. A. Mandrand-Berthelot, Mol. Microbiol., 1993, 9, 1181-1191.

17 C. Schmidt, C. Schwarzenberger, C. Grosse and D. H. Nies, J. Bacteriol., 2014, 196, 3461-3471.

18 G. Grass, S. Franke, N. Taudte, D. H. Nies, L. M. Kucharski, M. E. Maguire and C. Rensing, J. Bacteriol., 2005, 187, 1604-1611.

19 G. Grass, M. D. Wong, B. P. Rosen, R. L. Smith and C. Rensing, J. Bacteriol., 2002, 184, 864-866.

20 N. Taudte and G. Grass, BioMetals, 2010, 23, 643-656.

21 M. Herzberg, L. Bauer and D. H. Nies, Metallomics, 2014, 6, 421-436.

22 M. Herzberg, D. Dobritzsch, S. Helm, S. Baginski and D. H. Nies, Metallomics, 2014, 6, 2157-2165.

23 M. Herzberg, M. Schüttau, M. Reimers, C. Grosse, H. G. Schlegel and D. H. Nies, Metallomics, 2015, 7, 632-649.

24 V. Lunin, E. Dobrovetsky, G. Khutoreskaya, R. Zhang, A. Joachimiak, D. A. Doyle, A. Bochkarev, M. E. Maguire, A. M. Edwards and C. M. Koth, Nature, 2006, 440, 833-837. 25 Y. Golan, B. Berman and Y. G. Assaraf, J. Biol. Chem., 2015, 290, 9050-9063.

26 D. H. Nies, A. Nies, L. Chu and S. Silver, Proc. Natl. Acad. Sci. U. S. A., 1989, 86, 7351-7355.

27 M. Mergeay, D. Nies, H. G. Schlegel, J. Gerits, P. Charles and F. van Gijsegem, J. Bacteriol., 1985, 162, 328-334.

28 D. Nies, M. Mergeay, B. Friedrich and H. G. Schlegel, J. Bacteriol., 1987, 169, 4865-4868.

29 H. Liesegang, K. Lemke, R. A. Siddiqui and H.-G. Schlegel, J. Bacteriol., 1993, 175, 767-778.

30 Y. Huang, P. Anderle, K. J. Bussey, C. Barbacioru, U. Shankavaram, Z. Y. Dai, W. C. Reinhold, A. Papp, J. N. Weinstein and W. Sadee, Cancer Res., 2004, 64, 4294-4301.

31 T. H. Mauchline, J. E. Fowler, A. K. East, A. L. Sartor, R. Zaheer, A. H. F. Hosie, P. S. Poole and T. M. Finan, Proc. Natl. Acad. Sci. U. S. A., 2006, 103, 17933-17938.

32 A. Legatzki, S. Franke, S. Lucke, T. Hoffmann, A. Anton, D. Neumann and D. H. Nies, Biodegradation, 2003, 14, 153-168.

33 D. H. Nies and G. Grass, in EcoSal - Escherichia coli and Salmonella: cellular and molecular biology, ed. A. Böck, R. Curtiss III, J. B. Kaper, F. C. Neidhardt, T. Nyström, K. E. Rudd and C. L. Squires, ASM Press, Washington, D.C., 2009, DOI: 10.1128/ecosal.5.4.4.3.

34 C. Rensing, B. Mitra and B. P. Rosen, Proc. Natl. Acad. Sci. U. S. A., 1997, 94, 14326-14331.

35 R. Sharma, C. Rensing, B. P. Rosen and B. Mitra, J. Biol. Chem., 2000, 275, 3873-3878. 
36 J. B. Liu, S. J. Dutta, A. J. Stemmler and B. Mitra, Biochemistry, 2006, 45, 763-772.

37 C. E. Outten, F. W. Outten and T. V. O'Halloran, J. Biol. Chem., 1999, 274, 37517-37524.

38 K. R. Brocklehurst, J. L. Hobman, B. Lawley, L. Blank, S. J. Marshall, N. L. Brown and A. P. Morby, Mol. Microbiol., 1999, 31, 893-902.

39 C. E. Outten and T. V. O'Halloran, Science, 2001, 292, 2488-2492.

40 K. Helbig, C. Bleuel, G. J. Krauss and D. H. Nies, J. Bacteriol., 2008, 190, 5431-5438.

41 M. P. Hensley, D. L. Tierney and M. W. Crowder, Biochemistry, 2011, 50, 9937-9939.

42 J. Goris, P. De Vos, T. Coenye, B. Hoste, D. Janssens, H. Brim, L. Diels, M. Mergeay, K. Kersters and P. Vandamme, Int. J. Syst. Evol. Microbiol., 2001, 51, 1773-1782.

43 A. Legatzki, A. Anton, G. Grass, C. Rensing and D. H. Nies, J. Bacteriol., 2003, 185, 4354-4361.

44 D. Koch, D. H. Nies and G. Grass, BioMetals, 2007, 20, 759-771.

45 A. Rodrigue, G. Effantin and M. A. Mandrand-Berthelot, J. Bacteriol., 2005, 187, 2912-2916.

46 J. Payandeh, C. Li, M. Ramjeesingh, E. Poduch, C. E. Bear and E. F. Pai, J. Biol. Chem., 2008, 283, 11721-11733.

47 K. M. Papp-Wallace, M. Nartea, D. G. Kehres, S. Porwollik, M. McClelland, S. J. Libby, F. C. Fang and M. E. Maguire, J. Bacteriol., 2008, 190, 6517-6523.

48 J. Kean, R. M. Cleverley, L. O'Ryan, R. C. Ford, S. M. Prince and J. P. Derrick, Mol. Membr. Biol., 2008, 25, 653-661.

49 S. Ishijima, Z. Shigemi, H. Adachi, N. Makinouchi and I. Sagami, Biochim. Biophys. Acta, Biomembr., 2012, 1818, 2202-2208.

50 R. Pfoh, A. Li, N. Chakrabarti, J. Payandeh, R. Pomes and E. F. Pai, Proc. Natl. Acad. Sci. U. S. A., 2012, 109, 18809-18814.

51 A. Guskov, N. Nordin, A. Reynaud, H. Engman, A. K. Lundback, A. J. O. Jong, T. Cornvik, T. Phua and S. Eshaghi, Proc. Natl. Acad. Sci. U. S. A., 2012, 109, 18459-18464.

52 M. Webb, Biochim. Biophys. Acta, 1970, 222, 428-439.

53 M. Lohmeyer and C. G. Friedrich, Arch. Microbiol., 1987, 149, 130-135.

54 D. H. Nies and S. Silver, J. Bacteriol., 1989, 171, 4073-4075.
55 S. J. Beard, R. Hashim, G. H. Wu, M. R. B. Binet, M. N. Hughes and R. K. Poole, FEMS Microbiol. Lett., 2000, 184, 231-235.

56 R. M. Harris, D. C. Webb, S. M. Howitt and G. B. Cox, J. Bacteriol., 2001, 183, 5008-5014.

57 R. J. Jackson, M. R. B. Binet, L. J. Lee, R. Ma, A. I. Graham, C. W. McLeod and R. K. Poole, FEMS Microbiol. Lett., 2008, 289, 219-224.

58 Z. M. Wang, A. Choudhary, P. S. Ledvina and F. A. Quiocho, J. Biol. Chem., 1994, 269, 25091-25094.

59 H. Rosenberg, R. G. Gerdes and K. Chegwidden, J. Bacteriol., 1977, 131, 505-511.

60 A. J. Worlock and R. L. Smith, J. Bacteriol., 2002, 184, 4369-4373.

61 K. M. Tan, A. Sather, J. L. Robertson, S. Moy, B. Roux and A. Joachimiak, Protein Sci., 2009, 18, 2043-2052.

62 J. Sambrook, E. F. Fritsch and T. Maniatis, Molecular cloning, a laboratory manual, Cold Spring Harbor Laboratory, Cold Spring Harbor, N.Y., 2nd edn, 1989.

63 R. Simon, U. Priefer and A. Pühler, Bio/Technology, 1983, 1, 784-791.

64 C. Große, S. Friedrich and D. H. Nies, J. Mol. Microbiol. Biotechnol., 2007, 12, 227-240.

65 C. J. Marx and M. E. Lidstrom, Biotechniques, 2002, 33, 1062-1067.

66 N. Suzuki, H. Nonaka, Y. Tsuge, M. Inui and H. Yukawa, Appl. Environ. Microbiol., 2005, 71, 8472-8480.

67 H. Albert, E. C. Dale, E. Lee and D. W. Ow, Plant J., 1995, 7, 649-659.

68 C. N. Pace and M. J. Scholtz, in Protein Structure: A Practical Approach, ed. T. Creighton, IRL Press, Oxford, UK, 1997, pp. 299-322.

69 A. Anton, A. Weltrowski, J. H. Haney, S. Franke, G. Grass, C. Rensing and D. H. Nies, J. Bacteriol., 2004, 186, 7499-7507.

70 M. H. Saier, Jr., C. V. Tran and R. D. Barabote, Nucleic Acids Res., 2006, 34, D181-186.

71 V. Deretic, S. Chandrasekharappa, J. F. Gill, D. K. Chatterjee and A. Chakrabarty, Gene, 1987, 57, 61-72.

72 D. H. Nies, J. Bacteriol., 1992, 174, 8102-8110.

73 K. Weber, J. R. Pringle and M. Osborn, Methods Enzymol., 1972, 26, 3-27.

74 M. Goldberg, T. Pribyl, S. Juhnke and D. H. Nies, J. Biol. Chem., 1999, 274, 26065-26070. 